\title{
Empirical Comparison of Coordinate Transformations from the Australian Geodetic Datum (AGD66 and AGD84) to the Geocentric Datum of Australia (GDA94)
}

\author{
R W Kinneen and W E Featherstone \\ Western Australian Centre for Geodesy, Department of Spatial Sciences, Curtin University of Technol- \\ ogy, GPO Box U1987, Perth WA 6845; Tel: (08) 9266 2734, Fax (08) 9266 2703, \\ robkinneen@bigpond.com W.Featherstone@curtin.edu.au,
}

Correspondence to: Will Featherstone

\begin{abstract}
This paper compares six coordinate transformation models and eight associated sets of (new and old) parameters over Australia. Test data comprising 161 Australian Geodetic Datum 1966 (AGD66) and 327 Australian Geodetic Datum 1984 (AGD84) coordinates are transformed to the Geocentric Datum of Australia 1994 (GDA94) using these different models and parameters. The transformed coordinates are then compared with the, mainly satellite-derived, GDA94 coordinates of the same ground marks (i.e., control), then the results analysed and discussed. It must be stressed that this paper does not attempt to investigate or analyse the suitability of the mathematical models themselves, but makes an empirical comparison of past and existing approaches and parameters by using the same sample data sets. It is shown, as could be expected, that the more recent transformation parameters are the most suitable for coordinate transformations from the AGD to the GDA and vice versa.
\end{abstract}

\section{INTRODUCTION}

There remains a large amount of interest in practical horizontal geodetic coordinate transformations in Australia, and this is likely to continue, due to the change from the Australian Geodetic Datum (AGD: 1966 and 1984 realisations) to the Geocentric Datum of Australia (GDA: 1994 realisation). However, there is a plethora of different transformation options available, each with a different level of stated accuracy that is often assumed for all locations, whereas it is more likely to vary as a function of posi- 
tion, especially for the conformal transformation models (cf. Featherstone, 1997). Quite often, users of the transformation models and associated parameters will not have the means to readily verify the stated accuracies, and thus assume that they hold true for all locations. For datasets requiring high transformation integrity, users will want to avoid weaknesses in the transformation performance. Therefore, it is useful to be aware of those regions where the transformation may not meet expectation, or may exceed it.

Regions that exhibit large transformation errors for some of the currently available models and parameters are already known to exist, such as around Exmouth and Esperance in Western Australia for the seven-parameter similarity transformation with the ICSM (2002a) parameters (e.g., Featherstone and Kinneen, 2001). However, these regions are not widely known to the users, nor are they reported during the transformation process, certainly not with the software provided by the Intergovernmental Committee on Surveying and Mapping (ICSM). If however these results were made available to users, they would have a reasonable guide as to what to expect from the chosen transformation method for a particular region. Users will also be more aware of localised regions of transformation performance, whether good or bad, and will be able to plan accordingly. This is one aim of this paper. Of course, the important qualifier to this is the quality of the user's own data; a transformation method simply cannot improve the quality of the source data.

Burford (1985), Harvey (1986), Steed (1990) and Featherstone (1997), among others, studied the then-available transformation models and parameters over Australia. Since those studies were conducted, several new sets of transformation parameters have been derived for some of the mathematical models tested and new transformation algorithms have been realised specifically for transformation to the GDA94 (ICSM, 2002a). However, unlike the study by Featherstone (1997), the study reported in the present paper compares the transformations with observed coordinates on both geodetic datums. Accordingly, it gives a more realistic indication of the current transformation accuracy. However, it is essential to acknowledge that the points used in this analysis were also used to determine some of the transformation parameters, and so correlations exist. Therefore, it is plausible that the accuracies indicated may be slightly overoptimistic.

In the current paper, six transformation models and eight sets of parameters were used to transform a data set, comprising 161 AGD66 and 327 AGD84 mostly first-order (as defined by ICSM, 2002b) geodetic control points across Australia, to the GDA94. 
The transformed coordinates were then compared with the observed GDA94 coordinates to assess their accuracy, with the best model and parameters giving the closest agreement between coordinates. This procedure is also used to map systematic differences, thus allowing an appraisal to be made of the good and bad areas of transformation accuracy. It is again acknowledged that the more definitive assessment will come from using points not used to compute the transformation parameters, but such data were not available to the authors at the time of this study.

\section{TRANSFORMATION MODELS AND PARAMETERS COMPARED}

The mathematical models will not be duplicated here. Instead, the reader is referred to the literature cited for each. However, it will be stated whether they are conformal or projective (cf. Featherstone, 1997). As is well known, transformation parameters are derived from a series of common points on each datum. They are called common points because the same ground monuments have coordinates on both the AGD and the GDA (or whatever datums). As there are normally many more common points than parameters to be solved, least squares techniques are used to gain an optimal estimate of the transformation parameters. Unfortunately however, the standard errors of the parameters are rarely published, as is the case for the ICSM (2002a) parameters. This does not allow for formal error propagation into the transformed coordinates, thus rendering the use of known points the only approach with which to verify the transformation accuracy.

Before proceeding, it is essential to point out the important, yet seemingly poorly understood, difference between transformations from the AGD to both the World Geodetic System 1984 (WGS84) and the GDA94. The GDA94 and WGS84 are two distinctly different datums, based on slightly different reference ellipsoids, and using different least squares adjustments of different observations. Therefore, while many sources (e.g., ICSM, 2002a) state that WGS84 and GDA94 agree at the $\pm 10 \mathrm{~cm} \mathrm{level,}$ this only applies globally and is an RMS value (cf. Malays and Slater, 1994). In the Australian context, AGD coordinates transformed to the WGS84 using one particular mathematical model and set of parameters will not agree with the GDA94 coordinates transformed using the same model and a different set of parameters. Moreover, the difference between these transformations is often greater than the stated $\pm 10 \mathrm{~cm}$ value. 
This is to be expected, but comments by several authors and agencies that the two datums are identical seem to us to be widely misinterpreted.

The transformation parameters to WGS84 used in this study were derived by the then Defense Mapping Agency in the United States (DMA; then the National Imagery and Mapping Agency, NIMA, and now the National Geospatial-intelligence Agency, NGA) in 1987 (NIMA, 1997) using approximately 100 common points in Australia, whose WGS84 coordinates had been determined by the DMA. The exception is Higgins's (1987) parameters, which were derived from old DMA parameters using an indirect technique, which will be described later. The transformation parameters to the GDA94 were derived by the ICSM in 1997, using many more common points on the AGD and GDA94. Therefore, simply by realising that different parameters have been derived by different agencies shows that there is a clear distinction between the resulting coordinates. Accordingly, users must remain sceptical about data that claims to be on WGS84 in Australia, questioning exactly how these coordinates were derived.

\section{Block Shift (Conformal) - new ICSM parameters}

This is the simplest technique to transform data from the AGD to the GDA94 but is also the least accurate, at least in theory, with an estimated accuracy of $5 \mathrm{~m}$ to $10 \mathrm{~m}$ (ICSM, 2002a). These parameters have been computed for 1:250,000 topographic map sheets across Australia, and are available from http://www.icsm.gov.au/icsm/gda/gdatm/index.html in terms of geodetic and MGA94 (i.e., UTM projection from the GRS80 ellipsoid) coordinates. The transformed GDA94/MGA94 coordinates of a new point are found by algebraically adding the shift values for the appropriate map sheet. (NB: remember to use negative latitude for the Southern Hemisphere). The shift values, by convention, represent the averaged or distance-weighted shift (between datums, i.e., observed and transformed) of points common to both datums for each map sheet. However, ICSM in 1997 used a slightly different method, which will be discussed in the Analysis of Results section. If the data are to be transformed cross 1:250,000 map-sheet boundaries, then disparities may occur from the different block shifts between adjacent blocks. 


\section{Molodensky Transformations (Conformal) - new ICSM parameters and old DMA parameters}

Depending upon one's viewpoint on the application of Molodensky transformation models, this can be classified as either a three- or five-parameter transformation. The three parameters comprise origin shifts of the geometrical centre of the reference ellipsoids associated with the datums, whereas the additional two parameters are changes in the semi-major axis and flattening of the reference spheroids associated with the two datums. However, the latter are still considered in the classical three-parameter approach, though at a different stage in the computations.

Table 1. Parameters for the Molodensky transformation models. For all transformations, the semi-minor axis of the ANS is $6378160 \mathrm{~m}$ and $\mathrm{f}=1 / 298.25$. The stated accuracies are approximately $5 \mathrm{~m}$ for each model.

\begin{tabular}{|l|r|r|r|r|}
\hline Model & \multicolumn{1}{|c|}{$\begin{array}{c}\text { Standard } \\
\text { NIMA (1997) }\end{array}$} & \multicolumn{2}{c|}{$\begin{array}{c}\text { Abridged } \\
\text { ICSM (2002a) }\end{array}$} \\
\hline From Datum & AGD66 & AGD84 & AGD66 & AGD84 \\
\hline To Datum & WGS84 & WGS84 & GDA94 & GDA94 \\
\hline$\Delta \mathrm{X}$ origin shift & $-133.0 \mathrm{~m}$ & $-134.0 \mathrm{~m}$ & $-127.8 \mathrm{~m}$ & $-128.5 \mathrm{~m}$ \\
\hline$\Delta \mathrm{Y}$ origin shift & $-48.0 \mathrm{~m}$ & $-48.0 \mathrm{~m}$ & $-52.3 \mathrm{~m}$ & $-53.0 \mathrm{~m}$ \\
\hline$\Delta \mathrm{Z}$ origin shift & $148.0 \mathrm{~m}$ & $149.0 \mathrm{~m}$ & $152.9 \mathrm{~m}$ & $153.4 \mathrm{~m}$ \\
\hline $\begin{array}{l}\Delta \mathrm{a} \text { difference in the semi-major } \\
\text { axis between ANS and GRS80 }\end{array}$ & $-23 \mathrm{~m}$ & $-23 \mathrm{~m}$ & $-23 \mathrm{~m}$ & $-23 \mathrm{~m}$ \\
\hline $\begin{array}{l}\Delta \text { f difference in the flattening } \\
\text { between ANS and GRS80 }\end{array}$ & $-81.204 \times 10^{-9}$ & $-81.204 \times 10^{-9}$ & $-81.19 \times 10^{-9}$ & $-81.19 \times 10^{-9}$ \\
\hline
\end{tabular}

There are two variants of the Molodensky transformation method: standard and abridged. The standard formulae require the spheroidal (ellipsoidal) height, whereas the abridged formulae do not. The rationale for the abridged formulae is that not all points to be transformed will have an associated height (cf. the discussion by Featherstone and Vanìček, 1999). However, the omission of the spheroidal height from the standard Molodensky formulae causes an error that is generally less than the stated accuracy of the transformation, especially for low-order datasets (e.g., Steed, 1995; ICSM, 2002b). Standard/abridged parameters for transformation to WGS 84 were derived by the DMA 
in 1987 (NIMA, 1997), and abridged parameters for transformation to GDA94 were derived by ICSM in 1997 (ICSM, 2002a). The latter parameters were derived from 161 AGD66 and 327 AGD84 common points across Australia. An abridged Molodensky transformation program to the GDA94 is available in spreadsheet from the ICSM web site at http://www.icsm.gov.au/icsm/gda/gdatm/index.html. All the above parameters are summarised in Table 1.

\section{Multiple Regression Equations (Projective) - old DMA parameters}

Multiple Regression Equations (MREs; e.g., Applebaum, 1984) model both the datum change and account for distortions between datums, which are normally larger for the older datums. The main advantage of this model over the conformal models is that better fits over continental size land areas can be achieved (NIMA, 1997; Featherstone, 1997). In 1987, the DMA produced a set of AGD66 and AGD84 to WGS84 transformation parameters, based on a polynomial formula in terms of normalised latitude and longitude, by comparing coordinates for approximately 90 stations over mainland Australia. To avoid the use of all polynomial terms, each is statistically tested to determine its significance. Those that are not significant are then omitted and the remaining parameters recomputed by least-squares techniques. The process is repeated iteratively until the bare minimum of significant parameters can be used in the MRE. Caution must be used to ensure that MREs are not extrapolated outside of the area of intended use, as large distortions can occur over very short distances (NIMA, 1997; Featherstone, 1997).

The AGD84 to WGS84 MRE parameters are:

$$
\begin{aligned}
\Delta \phi^{\prime \prime}=+ & 5.20604+0.25225 \mathrm{U}+0.58528 \mathrm{~V}-0.41584 \mathrm{U}^{2}-0.38620 \mathrm{UV}-0.06820 \mathrm{~V}^{2}+ \\
& 0.38699 \mathrm{U}^{2} \mathrm{~V}+0.07934 \mathrm{UV}^{2}+0.37714 \mathrm{U}^{4}-0.52913 \mathrm{U}^{4} \mathrm{~V}+0.38095 \mathrm{~V}^{7}+ \\
& 0.68776 \mathrm{U}^{2} \mathrm{~V}^{6}-0.03785 \mathrm{~V}^{8}-0.17891 \mathrm{U}^{9}-4.84581 \mathrm{U}^{2} \mathrm{~V}^{7}-0.35777 \mathrm{~V}^{9}+ \\
& 4.23859 \mathrm{U}^{2} \mathrm{~V}^{9}
\end{aligned}
$$

$\Delta \lambda "=+4.67877-0.73036 \mathrm{U}-0.57942 \mathrm{~V}+0.28840 \mathrm{U}^{2}+0.10194 \mathrm{U}^{3}-0.27814 \mathrm{UV}^{2}-$

$$
\begin{aligned}
& 0.13598 \mathrm{~V}^{3}+0.34670 \mathrm{UV}^{3}-0.46107 \mathrm{~V}^{4}+1.29432 \mathrm{~V}^{3} \mathrm{U}^{2}+0.17996 \mathrm{UV}^{4}- \\
& 1.13008 \mathrm{U}^{2} \mathrm{~V}^{5}-0.46832 \mathrm{U}^{8}+0.30676 \mathrm{~V}^{8}+0.31948 \mathrm{U}^{9}+0.16735 \mathrm{~V}^{9}-1.19443 \\
& \mathrm{U}^{3} \mathrm{~V}^{9}
\end{aligned}
$$

The AGD66 to WGS84 MREs are: 


$$
\begin{aligned}
\Delta \phi^{\prime \prime} & =+5.19238+0.12666 \mathrm{U}+0.52309 \mathrm{~V}-0.42069 \mathrm{U}^{2}-0.39326 \mathrm{UV}+0.93484 \mathrm{U}^{2} \mathrm{~V} \\
& +0.44249 \mathrm{UV}^{2}+0.30074 \mathrm{UV}^{3}+1.00092 \mathrm{U}^{5}-0.07565 \mathrm{~V}^{6}-1.42988 \mathrm{U}^{9}- \\
& 16.06639 \mathrm{U}^{4} \mathrm{~V}^{5}+0.07428 \mathrm{~V}^{9}+0.24256 \mathrm{UV}^{9}+38.27946 \mathrm{U}^{6} \mathrm{~V}^{7}-62.06403 \mathrm{U}^{7} \mathrm{~V}^{8}+ \\
& 89.19184 \mathrm{U}^{9} \mathrm{~V}^{8}
\end{aligned}
$$

$$
\begin{aligned}
\Delta \lambda "= & +4.69250-0.87138 \mathrm{U}-0.50104 \mathrm{~V}+0.12678 \mathrm{UV}-0.23076 \mathrm{~V}^{2}-0.61098 \mathrm{U}^{2} \mathrm{~V}- \\
& 0.38064 \mathrm{~V}^{3}+2.89189 \mathrm{U}^{6}+5.26013 \mathrm{U}^{2} \mathrm{~V}^{5}-2.97897 \mathrm{U}^{8}+5.43221 \mathrm{U}^{3} \mathrm{~V}^{5}- \\
& 3.40748 \mathrm{U}^{2} \mathrm{~V}^{6}+0.07772 \mathrm{~V}^{8}+1.08514 \mathrm{U}^{8} \mathrm{~V}+0.71516 \mathrm{UV}^{8}+0.20185 \mathrm{~V}^{9}+ \\
& 5.18012 \mathrm{U}^{2} \mathrm{~V}^{8}-1.72907 \mathrm{U}^{3} \mathrm{~V}^{8}-1.24329 \mathrm{U}^{2} \mathrm{~V}^{9}
\end{aligned}
$$

where $\mathrm{U}$ and $\mathrm{V}$ are the scaled and normalised latitude and longitude, respectively, and are given for Australia by

$$
\mathrm{U}=\mathrm{K}\left(\phi_{\mathrm{A}}+27^{\circ}\right) ; \quad \mathrm{V}=\mathrm{K}\left(\lambda_{\mathrm{A}}-134^{\circ}\right) ; \quad \mathrm{K}=0.05235988
$$

The stated accuracies of the transformation are $\sim 2$ m each (NIMA, 1997).

Note that ICSM (2002a) did not produce MREs for the AGD to GDA94 transformation. However, the so-called grid transformation (described later) would probably supersede any MRE that was developed.

\section{Seven-parameter Transformations (Conformal) - old Higgins parameters and new ICSM paramters}

The seven-parameter transformation is given numerous different names in the literature (e.g., Featherstone, 1997). Moreover, it can be applied in two subtly different ways, where the sign convention in the rotation can differ (e.g., Soler, 1998). Given a set of control or test coordinate values in both datums, the correct sign convention can easily be deduced. However, it is important to be aware of this potential problem, especially when using computer software developed by others.

The seven-parameter model used in Australia, and now endorsed by ICSM, is called the three-dimensional similarity transformation. For transformations between the AGD66 and GDA94, parameters can only be accurately computed for smaller (regional) areas where AGD66 is more consistent, with an accuracy of $\sim 1 \mathrm{~m}$ (Steed, 2001, pers comm.). These are available from the ICSM web site at http://www.icsm.gov.au/icsm/gda/gdatm/index.html. However, ICSM computed a na- 
tionwide set of AGD66 to GDA94 parameters, which were used in the formation of the grid-file transformation (Collier, 2002; described later).

For the AGD84, the two following parameter sets were compared (Table 2). Note that the Higgins parameters have now been superseded by the ICSM parameters, but their comparison is essential in the context of this paper.

Table 2. Parameters for the three-dimensional similarity transformation models. These are applied in matrix-vector form, so it necessary to convert between geodetic and Cartesian coordinates, which is given in, e.g., Featherstone (1997). It is also necessary to apply the rotations in radian measure.

\begin{tabular}{|l|r|r|}
\hline Parameters & ICSM (1997) & Higgins (1987) \\
\hline From Datum & AGD84 & AGD84 \\
\hline To Datum & GDA94 & WGS84 \\
\hline DX is the change of origin along the X axis & $-117.763 \mathrm{~m}$ & $-116.00 \mathrm{~m}$ \\
\hline DY is the change of origin along the Y axis & $-51.510 \mathrm{~m}$ & $-50.47 \mathrm{~m}$ \\
\hline DZ is the change of origin along the Z axis & $139.061 \mathrm{~m}$ & $141.69 \mathrm{~m}$ \\
\hline $\mathrm{R}_{\mathrm{X}}$ is the rotation of the X axis & $-0.292 ”$ & $-0.23 "$ \\
\hline $\mathrm{R}_{\mathrm{Y}}$ is the rotation of the Y & $-0.443 ”$ & $-0.39 "$ \\
\hline $\mathrm{R}_{\mathrm{Z}}$ is the rotation of the Z axis & $-0.277 ”$ & $-0.344 ”$ \\
\hline$S c$ is the change in scale in ppm. & -0.191 & 0.0983 \\
\hline
\end{tabular}

\section{New ICSM Parameters}

As with the three-parameter abridged Molodensky model, these parameters were computed from 327 common AGD84 and GDA94 points across Australia. These stations had well-determined, spirit-levelled Australian Height Datum (AHD) heights, and were used as GPS points in the national GDA94 adjustment (ICSM, 2002a). Although this model transforms the spheroidal (ellipsoidal) height, direct transformation of the height using the AUSGeoid98 geoid-ellipsoid separation (Featherstone et al., 2001) is much more accurate. The merits of the use of a conformal transformation that avoids heights (Featherstone and Vanicek, 1999) will not be replicated here. The AGD84 to GDA94 transformation parameters are available from the ICSM web site at http://www.icsm.gov.au/icsm/gda/gdatm/index.html. 


\section{Old Higgins (Interim) Parameters}

The Higgins (1987) parameters give the transformation from the AGD84 to WGS84 by an indirect method that was staged via three datums and one satellite ephemeris (position information). In conjunction with the DMA parameters, Higgins computed these parameters in three steps:

Step 1. WGS $84<>$ WGS72

Step 2. WGS72<> NSWC-9Z2

\section{Step 3. NSWC-9Z2<>AGD84}

Each step defined the spatial relationship between two coordinate systems in terms of seven parameters (Table 3). Higgins then combined these parameters to form a one-step coordinate transformation parameter set between the AGD84 and WGS84 datums using the simple laws of matrix algebra (Higgins, 1987).

Table 3. Derivation of the Higgins WGS84<>AGD84 transformation parameters

\begin{tabular}{|c|c|c|c|c|}
\hline Parameter & Step 1 & Step 2 & Step 3 & Solution \\
\hline & WGS84<>WGS72 & WGS72<>NSWC-9Z2 & NSWC-9Z2<>AGD84 & WGS84<>AGD84 \\
\hline $\mathrm{DX}(\mathrm{m})$ & 0.0 & 0.0 & 116.00 & 116.00 \\
\hline DY (m) & 0.0 & 0.0 & 50.47 & 50.47 \\
\hline DZ (m) & -4.5 & 0.0 & -137.19 & -141.69 \\
\hline $\operatorname{Rx}(\sec )$ & 0.0 & 0.0 & 0.23 & 0.23 \\
\hline Ry (sec) & 0.0 & 0.0 & 0.39 & 0.39 \\
\hline $\mathrm{Rz}(\mathrm{sec})$ & 0.554 & 0.26 & -0.47 & 0.344 \\
\hline Sc (ppm) & -0.2263 & 0.827 & -0.699 & -0.0983 \\
\hline
\end{tabular}

Note: The NSWC-9Z2 is a coordinate system used with the precise ephemeris of the TRANSIT Doppler navigation system. It was used for the satellite positions in the Geodetic Model of Australia 1982 (GMA82; Allman and Veenstra, 1984) which would become the AGD84 (NMC, 1986). When, in 1987, it was decided that a set of transformation parameters was needed between the AGD84 and the WGS84, the NSWC-9Z2 system was used to link the AGD84 datum to the WGS84 datum via the WGS72 datum. 
Firstly, a relationship between the WGS84 and WGS72 datums was defined in terms of seven parameters (Table 3 Step 1) (NIMA, 1997). Secondly, a relationship between the WGS72 datum and the NSWC-9Z2 system was defined in terms of seven parameters (Table 3 Step 2) (Seppelin, 1974). Thirdly, a relationship between the NSWC$9 \mathrm{Z2}$ system and the AGD84 datum was defined in terms of seven parameters (Table 3 Step 3) (Allman and Veenstra, 1984). It was then a simple matter of combining the three steps to form the WGS84<>AGD84 coordinate transformation parameters (Table 3 Column 5).

\section{The Grid Transformation (Projective) - new ICSM approach and data-file}

As with the MREs, the so-called grid transformation technique is able to model the change of datum as well as the distortion between the geodetic networks (cf. Collier et $a l .$, 1997). This is done by first creating a regularly spaced grid of unique, predetermined transformation shift values and mapping them to each grid node, from which they can be used as required to produce interpolated values for any given point. Collier (2002) performed a seven-parameter (conformal) transformation of irregularly spaced geodetic coordinates on the AGD, and compared them with the same observed geocentric coordinates (control) on the GDA94 in order to determine the distortions at each point. He then applied least-squares collocation (e.g., Moritz, 1980b) to grid these irregularly spaced coordinates in order to model a weighted datum shift and distortion shift (in latitude and longitude) for each node they surrounded (Figure 1). The initial use of a seven-parameter transform is required to remove the mean datum difference, which would prevent the correct use of least squares collocation. At present, the values used for the RMS noise and correlation length in the collocation are unknown, which prevents an independent analysis of these values. 


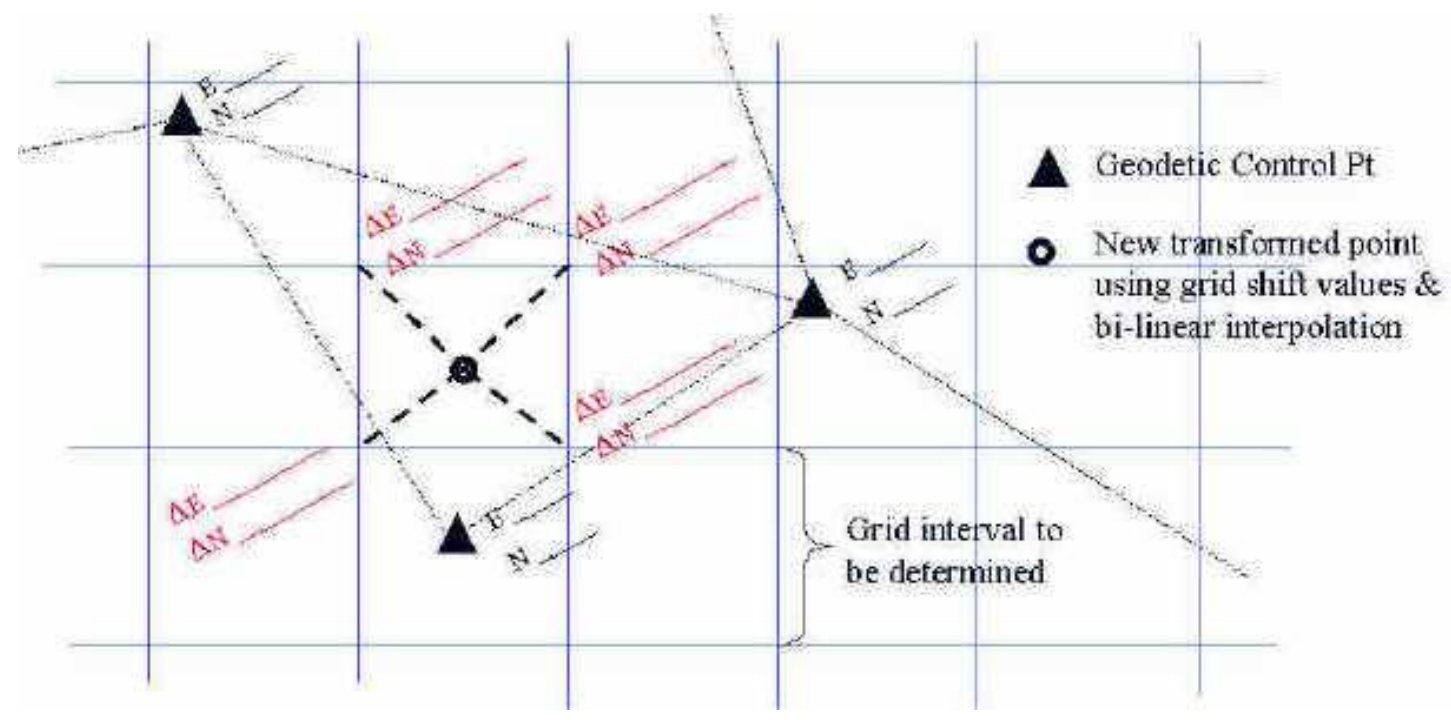

Figure 1. Schematic of distortion modelling in a geodetic network (Source: DOLA)

The data format used is the proprietary NTv2 format (though it does have some subtle variants), which allows for variable grid spacings. This is necessary to reduce interpolation errors by using a denser grid in areas where the distortions between datums are large, balanced against the size of the data file. The appropriate datum transformation program (given later) finds the shift values of the four nearest grid nodes for any point on the AGD, performs a simple bi-linear interpolation (Collier, 2002) and computes the shift values of the new point and hence gives its transformed coordinates on the GDA94. Transformation software is available for free download from the ICSM web site at http://www.icsm.gov.au/icsm/gda/gdatm/index.html.

\section{Summary}

Table 4 summarises the transformation parameters, the source from which each set was derived, as well as the published horizontal accuracies associated with each transformation model. These must not be used for vertical datum transformations; instead, AUSGeoid98 (Featherstone et al., 2001) or its successor must always be used in Australia. 
Table 4. Parameters used in the six horizontal datum transformation models.

\begin{tabular}{|c|c|c|c|c|c|c|c|c|}
\hline \multirow{2}{*}{\begin{tabular}{|c} 
Mathematical \\
Model
\end{tabular}} & \multirow{2}{*}{$\begin{array}{c}\text { Block } \\
\text { Shift } \\
\\
\text { ICSM } \\
\text { (1997) }\end{array}$} & \multicolumn{2}{|c|}{$\begin{array}{c}\text { Abridged } \\
\text { Molodensky }\end{array}$} & \multirow{2}{*}{\begin{tabular}{|c}
$\begin{array}{c}\text { Standard } \\
\text { Molodensky }\end{array}$ \\
DMA
\end{tabular}} & \multirow{2}{*}{$\begin{array}{c}\begin{array}{c}\text { Multiple } \\
\text { Regression } \\
\text { Equations }\end{array} \\
\text { DMA }\end{array}$} & \multicolumn{2}{|c|}{$\begin{array}{c}\text { 3-D } \\
\text { Similarity }\end{array}$} & \multirow{2}{*}{$\begin{array}{c}\text { Grid-file } \\
\text { ICSM }\end{array}$} \\
\hline & & ICSM & DMA & & & ICSM & Higgins & \\
\hline AGD66 & (1997) & (1997) & (1987) & (1987) & (1987) & (1997) & -- & (2001) \\
\hline AGD84 & & (1997) & (1987) & (1987) & (1987) & (1997) & (1987) & (2001) \\
\hline From datum & AGD & AGD & AGD & AGD & AGD & AGD & AGD & AGD \\
\hline To datum & GDA94 & GDA94 & WGS84 & WGS84 & WGS84 & GDA94 & WGS84 & GDA94 \\
\hline $\begin{array}{l}\text { Published } \\
\text { Accuracies }\end{array}$ & $(5-10 m)$ & $(5 \mathrm{~m})$ & $(5 \mathrm{~m})$ & $(5 \mathrm{~m})$ & $(2 \mathrm{~m})$ & (1m) & unspecified & $(5-10 \mathrm{~cm})$ \\
\hline
\end{tabular}

\section{EVALUATION METHODOLOGY}

The test procedure was implemented by transforming the 161 AGD66 and 327 AGD84 (mostly first-order; ICSM, 2002a) geodetic control points, kindly supplied by ICSM, to the GDA94, then comparing the transformed coordinates with the observed GDA94 coordinates of the same ground marks. This was done using six transformation methods and their associated transformation parameter sets (Table 4). The resultant positional differences between the observed and transformed coordinates then revealed the actual accuracy of each transformation model and associated transformation parameter set. However, it is essential to point out that some of the transformation parameters were derived using exactly these same control points (i.e., the ICSM abridged Molodensky and ICSM similarity transformation parameters), which causes a bias in the results. This will be discussed later.

The method for calculating the positional differences between the observed GDA94 and the transformed GDA94 coordinates employed Pythagoras's formula on the sphere, as follows. For the GRS80 ellipsoid (Moritz, 1980a), which is associated with the GDA94, one second of arc in latitude and longitude is equal to $30.9 \mathrm{~m}$ of ground distance at the equator. This value is found by dividing the circumference of GRS80 at the equator by $360^{\circ}$. The longitudes, in seconds of arc, of points common to both datums were differenced, multiplied by 30.9 , and then multiplied by the cosine of the observed latitude (to compensate for meridional convergence). The procedure was 
repeated for the latitudes, only without compensating for meridional convergence. These values were then squared, summed and the square root taken, giving the positional differences (hypotenuses) in metres. Of course alternative methods, such as the distance computed from the inverse geodetic problem (e.g., Vincenty, 1975) can be used, but the approximate use of the Pythagorean approach yielded the same conclusions with considerably less computational effort.

The analysis method adopted gives a more realistic mean and standard deviation of the differences, as there are no negatives in the data and thus values do not cancel one another (cf. Collier and Bowden, 1999). This avoids computing an overly optimistic mean (and because the standard deviation is based on the mean, an overly optimistic mean will also give a pessimistic standard deviation) and thus a misleading statistic. Take the following case of a person who wants to know how incorrect their transformed position is, they are not normally concerned with the direction of the error, only the magnitude of that error. Therefore, it is more appropriate to combine the difference in latitude and longitude, rather than consider them separately (cf. Collier and Bowden, 1999). Of course, if directional information is important, then the vector differences (i.e., both magnitude and direction) need to be computed.

\section{Statistical Assessment}

In statistical assessments, large gross errors are usually detected and removed. Generally the critical value between good and bad data is computed from the formula: one mean plus-or-minus three standard deviations -- the so-called $\mathrm{Z}$ score of three. Data beyond this critical value are considered as being too unrealistic to have been caused by random errors, according to the laws of probability (for large samples), and are assumed to have been caused by gross errors. These are often removed and the mean and standard deviation re-computed, from which the data set is analysed.

Systematic errors, however, do not follow a random probability distribution and thus must be compensated for and thus removed in different ways, if at all possible. If, however, a data set contains systematic errors, there is no point in testing it for bad data by using a Z-score test that is based on random errors. The reason for this is because the mean and standard deviation will have been influenced by those systematic errors, which means they will not be truly representative of the random behaviour of the data. 
Therefore, since it is well known that systematic errors exist between datums (this is why projective transformations are necessary), all the test data were used in the following statistical assessments. This was demonstrated by the simple use of histograms (not presented here for the sake of preserving space). Also, the authors felt that the removal of apparently bad points based on a somewhat arbitrary Z-score would not provide a true representation of transformation performance between models. Moreover, it is important for users to be shown that areas of poor transformation accuracy do exist.

\section{ADDITIONAL CONSIDERATIONS}

Before examining the results of the transformed data sets of 161 AGD66 and 327 AGD84 points, some influencing factors need to be discussed. The two main factors that affect the quality of coordinate transformations are 1. Network distortions (i.e., systematic errors), and 2. The spatial distribution of points, which can cause transformation parameter biases.

\section{Network Distortions}

Distortions in local geodetic networks are commonplace. They may be due to systematic errors in the data or approximate reductions, and affect mainly the scale and orientation of the network. In Australia, systematic errors have gradually crept into the AGD network because of the past practice of approximate observation reductions (eg. ignoring the geoid-ellipsoid separation or deflection of the vertical) and from approximate adjustment procedures (Featherstone and Rüeger, 2000).

Solving for a number of sets of local parameters, which better represent the local and regional areas, rather than determining one set of parameters for the whole of the continent, is the best way to avoid propagating distortions in conformal transformations. Transformation parameters over a large area will represent mean values of scale, rotation and translation for the areas and will tend to generalise distortions. Therefore the total network should be divided into sub-networks to check consistency throughout the whole area (Harvey, 1986). Figure 2 shows how distortions in a network affect transformation accuracy. In the Exmouth and Esperance regions (Western Australia) the ICSM similarity transformation accuracy is noticeably lower, as well as in remote areas of Queensland and the Northern Territory. Elsewhere the accuracy is more consistent. 


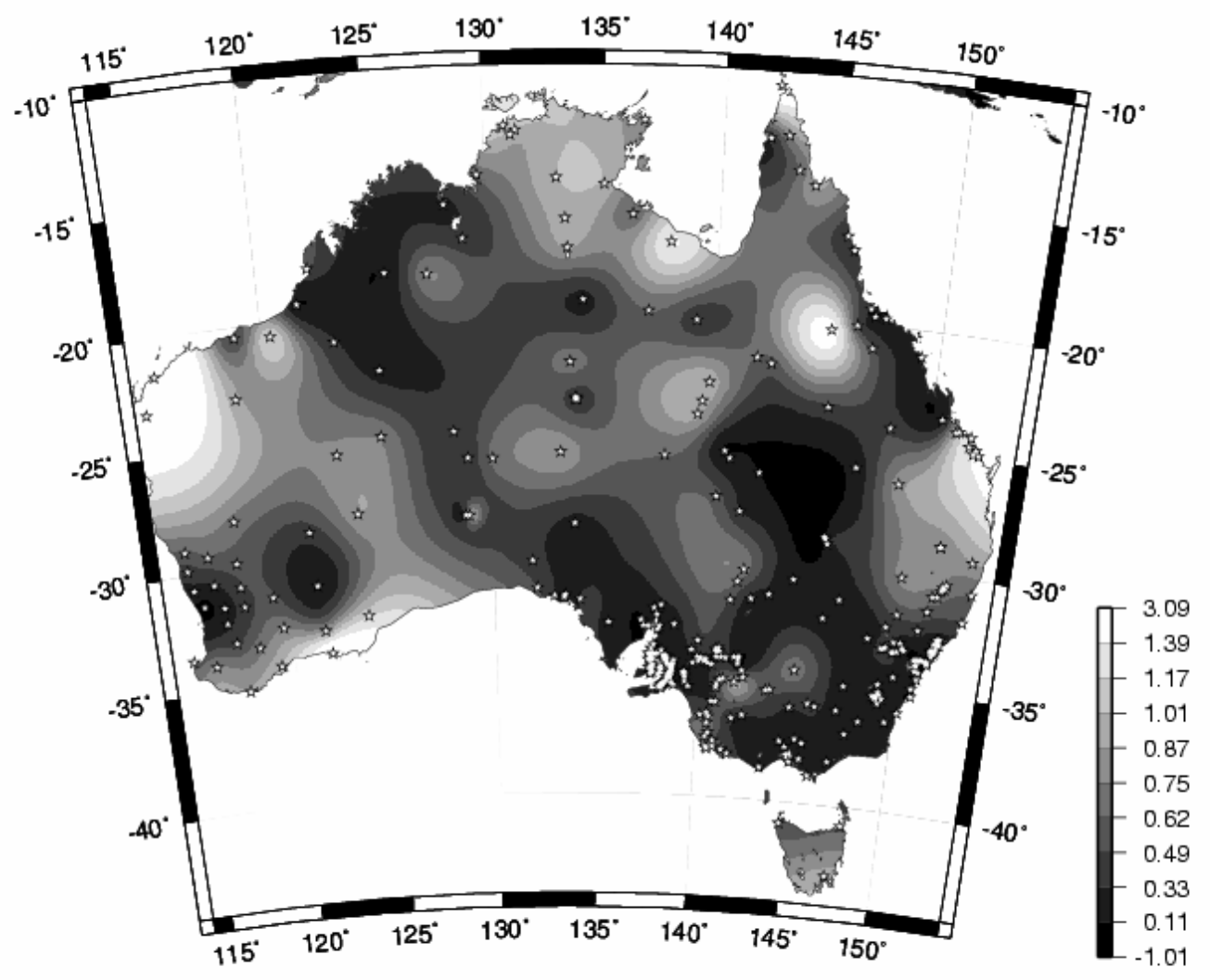

Figure 2. Interpolated contour map showing the magnitude of distortions across Australia, using the similarity transformation model with ICSM AGD84 to GDA94 transformation parameters compared to 327 control points (units in metres).

\section{Spatial Distribution of Points}

The accuracy of the estimated parameters for each transformation model may vary considerably as a function of position, especially for the conformal models (cf. Figure 3). This depends on the spatial distribution of the points used both to estimate and evaluate the parameters. For a stable parameter solution, it is important that the points are spatially well distributed. For example, a network with an uneven geographical spread of points will cause the parameters to be biased towards the areas of high point density. This means that points in areas of low density will be disadvantaged, as the parameters will not necessarily reflect the difference between datums nearly as well for their region. Of course, this can be accounted for through appropriate spatial weighting, but this is rarely used in practise. 
However, it is important to note that this factor is governed solely by the presence of network distortions. If no distortions existed, the conformal transformation parameters would be equally representative across the entire region and a perfect transformation would result, provided that the correct mathematical model had been adopted. However, because distortions do exist and because the transformation parameters implicitly include the imperfect (distorted) datum change, point distribution causes biases in the formation of these parameters. For example, if the points are more densely distributed over South Australia and this region contains large distortions in a southeasterly direction, the computed transformation parameters will compensate by pulling the network in a large degree towards the northwest. If the rest of the nation contains distortions in a northwest direction, then the parameters will, when used in the transformation process, further distort the network (for those regions).

To further illustrate this, ICSM's AGD84 to GDA94 transformation parameters for the three-dimensional similarity method were estimated using 327 points across Australia. Of these, 107 and 115 are located in South Australia and southeastern Australia respectively. This translates to $33 \%$ and $35 \%$ of the total points used, which produces a parameter bias of a factor of nearly two for these regions (Table 6). As can be seen in Figure 13, these regions clearly have fewer remaining distortions post transformation, and so the transformation parameters are well suited to them.

A second bias is caused when the same points used to estimate the transformation parameters are used to test the transformation. Because the parameters were modelled on these points, they will be more suited to them. This will therefore cause the results to appear slightly better than they in fact are (as compared with truly independent points). In this study all (and only) 327 AGD84 points were used and therefore, together with the afore-mentioned parameter bias, what we loosely term a double bias will exist in South Australia and south-eastern Australia.

A final factor in transformation parameter estimation is to avoid the situation of co-linearity between points. This is because components of rotations about axes parallel to the line of points cannot be determined (Harvey, 1986). This reduces the accuracy of the rotation parameters, and in a seven-parameter conformal transformation the accuracy of the entire set is therefore reduced. However, this facet will not be investigated here. 


\section{ANALYSIS OF RESULTS}

Tables 5 and 6 show the results of the transformations from the AGD66/84 to the GDA94 using the six transformation methods and eight associated parameter sets.

\section{Block Shift - new ICSM data}

From Table 5, and as can be seen in Figures 3 and 4, the low accuracy (stated at 5-10m in ICSM, 2002a) block shift model for the AGD66 is better than for the AGD84 (and also better than the medium accuracy models, as will be discussed later), with means of $0.956 \mathrm{~m}$ and $4.677 \mathrm{~m}$ and standard deviations of $0.597 \mathrm{~m}$ and $5.034 \mathrm{~m}$, respectively. The reason for this is because ICSM computed the block shifts in an arguably unconventional manner.

Table 5. Descriptive statistics of the magnitudes of the positional differences between transformed GDA94 (from AGD66) coordinates and observed GDA94 coordinates at all 161 available points across Australia using six mathematical models and seven associated parameter sets (units in metres).

\begin{tabular}{|c|c|c|c|c|c|c|c|}
\hline Model & $\begin{array}{l}\text { Block } \\
\text { Shift }\end{array}$ & \multicolumn{2}{|c|}{ Abridged $\underset{\text { sky }}{\text { Moloden- }}$} & \multirow{2}{*}{$\begin{array}{c}\begin{array}{c}\text { Standard } \\
\text { Molodensky }\end{array} \\
\text { DMA } \\
(1987)\end{array}$} & \multirow{2}{*}{$\begin{array}{c}\begin{array}{c}\text { Multiple } \\
\text { Regression } \\
\text { Equations }\end{array} \\
\text { DMA } \\
(1987)\end{array}$} & \multirow{2}{*}{$\begin{array}{c}\text { 3-D } \\
\text { Similarity } \\
\text { ICSM } \\
\text { (1997) } \\
\text { Regional }\end{array}$} & \multirow{2}{*}{$\begin{array}{c}\text { Grid-file } \\
\\
\text { ICSM } \\
(09-2001) \\
\text { A66 Na- } \\
\text { tional }\end{array}$} \\
\hline Parameters & $\begin{array}{l}\text { ICSM } \\
(1997)\end{array}$ & $\begin{array}{l}\text { ICSM } \\
(1997)\end{array}$ & $\begin{array}{l}\text { DMA } \\
(1987)\end{array}$ & & & & \\
\hline From & AGD66 & AGD66 & AGD66 & AGD66 & AGD66 & AGD66 & AGD66 \\
\hline To & GDA94 & GDA94 & WGS84 & WGS84 & WGS84 & GDA94 & GDA94 \\
\hline \multicolumn{8}{|c|}{ WA $(34)$} \\
\hline Min & 0.190 & 0.253 & 0.335 & 0.335 & 0.302 & \multirow[t]{4}{*}{ NA } & 0.004 \\
\hline Max & 3.800 & 4.346 & 6.468 & 6.468 & 10.742 & & 1.136 \\
\hline Std & 0.760 & 1.026 & 1.629 & 1.629 & 2.412 & & 0.223 \\
\hline Mean & 1.297 & 2.128 & 2.725 & 2.725 & 2.179 & & 0.198 \\
\hline \multicolumn{8}{|c|}{ SA (40) } \\
\hline Min & 0.085 & 0.531 & 0.766 & 0.766 & 0.259 & \multirow[t]{4}{*}{ NA } & 0.007 \\
\hline Max & 2.198 & 3.125 & 3.145 & 3.145 & 1.976 & & 0.471 \\
\hline Std & 0.575 & 0.586 & 0.525 & 0.526 & 0.415 & & 0.114 \\
\hline Mean & 0.833 & 1.668 & 1.766 & 1.771 & 0.935 & & 0.098 \\
\hline \multicolumn{8}{|c|}{ Qld (24) } \\
\hline Min & 0.166 & 0.457 & 0.847 & 0.847 & 0.262 & \multirow[t]{4}{*}{ NA } & 0.012 \\
\hline $\operatorname{Max}$ & 2.526 & 5.201 & 8.482 & 8.482 & 2.587 & & 2.336 \\
\hline Std & 0.569 & 1.002 & 1.797 & 1.796 & 0.764 & & 0.530 \\
\hline Mean & 0.960 & 1.616 & 2.380 & 2.387 & 1.261 & & 0.261 \\
\hline \multicolumn{8}{|c|}{ NT (12) } \\
\hline Min & 0.423 & 0.685 & 0.831 & 0.831 & 0.626 & 0.197 & 0.011 \\
\hline Max & 1.501 & 3.359 & 3.814 & 3.814 & 3.225 & 1.658 & 0.126 \\
\hline Std & 0.369 & 0.814 & 0.840 & 0.839 & 0.854 & 0.485 & 0.035 \\
\hline Mean & 0.956 & 2.106 & 1.815 & 1.817 & 1.598 & 1.033 & 0.047 \\
\hline \multicolumn{8}{|c|}{ Nsw/Vic/Tas (51) } \\
\hline
\end{tabular}




\begin{tabular}{|l|c|c|c|c|c|c|c|}
\hline Min & 0.228 & 0.387 & 0.213 & 0.213 & 0.084 & 0.093 & 0.003 \\
\hline Max & 2.270 & 1.730 & 2.120 & 2.121 & 4.029 & 1.276 & 0.230 \\
\hline Std & 0.460 & 0.365 & 0.487 & 0.490 & 0.870 & 0.238 & 0.043 \\
\hline Mean & 0.822 & 1.014 & 1.034 & 1.035 & 0.986 & 0.445 & 0.039 \\
\hline \multicolumn{7}{|c|}{ National (161) } \\
\hline Min & 0.085 & 0.253 & 0.213 & 0.214 & 0.084 & 0.093 & 0.003 \\
\hline Max & 3.800 & 5.201 & 8.482 & 8.482 & 10.742 & 1.658 & 2.336 \\
\hline Std & 0.597 & 0.849 & 1.273 & 1.273 & 1.359 & 0.378 & 0.248 \\
\hline Mean & 0.956 & 1.583 & 1.832 & 1.835 & 1.312 & 0.559 & 0.121 \\
\hline \multicolumn{7}{|l|}{} \\
\hline $\begin{array}{l}\text { Published } \\
\text { Accuracies }\end{array}$ & $(5-10 \mathrm{~m})$ & $(5 \mathrm{~m})$ & $(5 \mathrm{~m})$ & $(5 \mathrm{~m})$ & $(2 \mathrm{~m})$ & $(1 \mathrm{~m})$ & $(5-10 \mathrm{~cm})$ \\
\hline
\end{tabular}

Table 6. Descriptive statistics of the magnitudes of the positional differences between transformed GDA94 (from AGD84) coordinates and observed GDA94 coordinates at all 327 points available across Australia using six mathematical models and eight associated parameter sets (units in metres).

\begin{tabular}{|c|c|c|c|c|c|c|c|c|}
\hline \multirow{2}{*}{$\begin{array}{c}\text { Model } \\
\text { Parameters }\end{array}$} & \multirow{2}{*}{$\begin{array}{c}\begin{array}{c}\text { Block } \\
\text { Shift }\end{array} \\
\text { ICSM } \\
(1997)\end{array}$} & \multicolumn{2}{|c|}{ Abridged ${ }_{\text {sky }}$ Moloden- } & \multirow{2}{*}{$\begin{array}{c}\begin{array}{c}\text { Standard } \\
\text { Moloden- } \\
\text { sky }\end{array} \\
\text { DMA } \\
(1987)\end{array}$} & \multirow{2}{*}{$\begin{array}{c}\begin{array}{c}\text { Multiple } \\
\text { Regression } \\
\text { Equations }\end{array} \\
\text { DMA } \\
(1987)\end{array}$} & \multicolumn{2}{|c|}{$\begin{array}{c}\text { 3-D } \\
\text { Similarity }\end{array}$} & \multirow{2}{*}{$\begin{array}{c}\text { Grid-file } \\
\\
\text { ICSM } \\
(07-2001) \\
\text { National } \\
84 \\
\end{array}$} \\
\hline & & $\begin{array}{r}\text { ICSM } \\
(1997)\end{array}$ & $\begin{array}{l}\text { DMA } \\
(1987)\end{array}$ & & & $\begin{array}{l}\text { ICSM } \\
(1997)\end{array}$ & $\begin{array}{l}\text { Higgins } \\
(1987)\end{array}$ & \\
\hline From & AGD84 & AGD84 & AGD84 & AGD84 & AGD84 & AGD84 & AGD84 & AGD84 \\
\hline To & GDA94 & GDA94 & WGS84 & WGS84 & WGS84 & GDA94 & WGS84 & GDA94 \\
\hline \multicolumn{9}{|c|}{ WA (46) } \\
\hline Min & 0.155 & 0.207 & 0.333 & 0.329 & 0.194 & 0.044 & 0.144 & 0.0 \\
\hline Max & 24.550 & 2.590 & 4.462 & 4.461 & 2.531 & 2.765 & 2.525 & 1.809 \\
\hline Std & 6.100 & 0.492 & 0.796 & 0.798 & 0.492 & 0.517 & 0.450 & 0.274 \\
\hline Mean & 6.516 & 0.982 & 1.929 & 1.926 & 0.836 & 0.666 & 0.679 & 0.063 \\
\hline \multicolumn{9}{|c|}{ SA (107) } \\
\hline Min & 0.148 & 0.066 & 0.057 & 0.052 & 0.105 & 0.062 & 0.106 & 0.002 \\
\hline Max & 17.345 & 1.068 & 1.435 & 1.436 & 1.730 & 0.738 & 1.495 & 0.896 \\
\hline Std & 3.401 & 0.222 & 0.225 & 0.224 & 0.246 & 0.151 & 0.288 & 0.206 \\
\hline Mean & 2.889 & 0.567 & 0.308 & 0.310 & 1.210 & 0.299 & 0.846 & 0.121 \\
\hline \multicolumn{9}{|c|}{ Qld (39) } \\
\hline Min & 0.267 & 0.119 & 0.700 & 0.705 & 0.150 & 0.040 & 0.091 & 0.005 \\
\hline Max & 22.958 & 3.111 & 5.802 & 5.805 & 2.711 & 1.921 & 1.751 & 0.362 \\
\hline Std & 7.288 & 0.573 & 1.040 & 1.040 & 0.557 & 0.478 & 0.443 & 0.081 \\
\hline Mean & 7.178 & 1.145 & 2.453 & 2.459 & 1.147 & 0.687 & 0.813 & 0.069 \\
\hline \multicolumn{9}{|c|}{ NT (20) } \\
\hline Min & 0.264 & 0.256 & 1.493 & 1.495 & 0.253 & 0.264 & 0.161 & NA \\
\hline Max & 20.055 & 2.016 & 3.956 & 3.958 & 1.781 & 1.405 & 1.284 & \\
\hline Std & 6.365 & 0.416 & 0.828 & 0.824 & 0.454 & 0.292 & 0.270 & \\
\hline Mean & 5.566 & 0.871 & 2.237 & 2.246 & 1.010 & 0.755 & 0.776 & \\
\hline \multicolumn{9}{|c|}{ Nsw/Vic/Tas (115) } \\
\hline Min & 0.148 & 0.023 & 0.353 & 0.356 & 0.214 & 0.034 & 0.194 & NA \\
\hline Max & 20.308 & 2.096 & 2.471 & 2.470 & 3.857 & 1.730 & 1.800 & \\
\hline Std & 3.989 & 0.308 & 0.479 & 0.479 & 0.555 & 0.247 & 0.221 & \\
\hline Mean & 4.603 & 0.549 & 1.524 & 1.525 & 1.460 & 0.340 & 0.860 & \\
\hline \multicolumn{9}{|c|}{ National (327) } \\
\hline Min & 0.148 & 0.023 & 0.057 & 0.052 & 0.105 & 0.034 & 0.091 & 0.0 \\
\hline Max & 24.550 & 3.111 & 5.802 & 5.805 & 3.857 & 2.765 & 2.525 & 0.809 \\
\hline Std & 5.034 & 0.426 & 0.979 & 0.979 & 0.503 & 0.358 & 0.321 & 0.208 \\
\hline Mean & 4.677 & 0.706 & 1.338 & 1.339 & 1.225 & 0.438 & 0.819 & 0.097 \\
\hline $\begin{array}{l}\text { Published } \\
\text { Accuracies }\end{array}$ & $(5-10 m)$ & $(5 \mathrm{~m})$ & $(5 \mathrm{~m})$ & $(5 \mathrm{~m})$ & $(2 \mathrm{~m})$ & $(1 \mathrm{~m})$ & -- & $(5-10 \mathrm{~cm})$ \\
\hline
\end{tabular}




\section{Footnotes to Table 6}

\section{$\underline{\text { AGD66-GDA94 }}$}

1. A total of 559 stations were selected as map centres on the AGD66.

2. The average shift between AGD66 and AGD84 common points surrounding each map centre was assigned to the map centres. (They each now have averaged AGD84 coordinates.)

3. The map centres were then transformed to the GDA94 using the sevenparameter similarity transformation.

4. The residuals (lat, long) between the transformed and observed coordinates for each map centre are the block shifts for points over an area $100 * 150 \mathrm{~km}$.

\section{$\underline{\text { AGD84-GDA94 }}$}

1. A total of 559 stations were selected as map centres on the AGD84.

2. The map centres were transformed to the GDA94 using the seven-parameter similarity transformation.

3. The residuals (lat, long) between the transformed and observed coordinates for each map centre are the block shifts for points over an area $100^{*} 150 \mathrm{~km}$.

From Table 6, the block shifts for the AGD66 are therefore a combination of the block shift and seven-parameter transformation models, while the AGD84 shifts are a straight seven-parameter transformation of map centres representing large areas. Because the AGD66 map centres were constrained to represent averaged AGD84 values before the seven-parameter transformation was applied, they were more representative of the distortions in their region than were the AGD84 map centres and were able to produce a more realistic transformation. This can be seen in Tables 5 and 6 and in Figures 3 and 4. Note the large minimum-maximum range and high standard deviations in Table 6, reflecting the generalised trend in the shifts for the AGD84. 


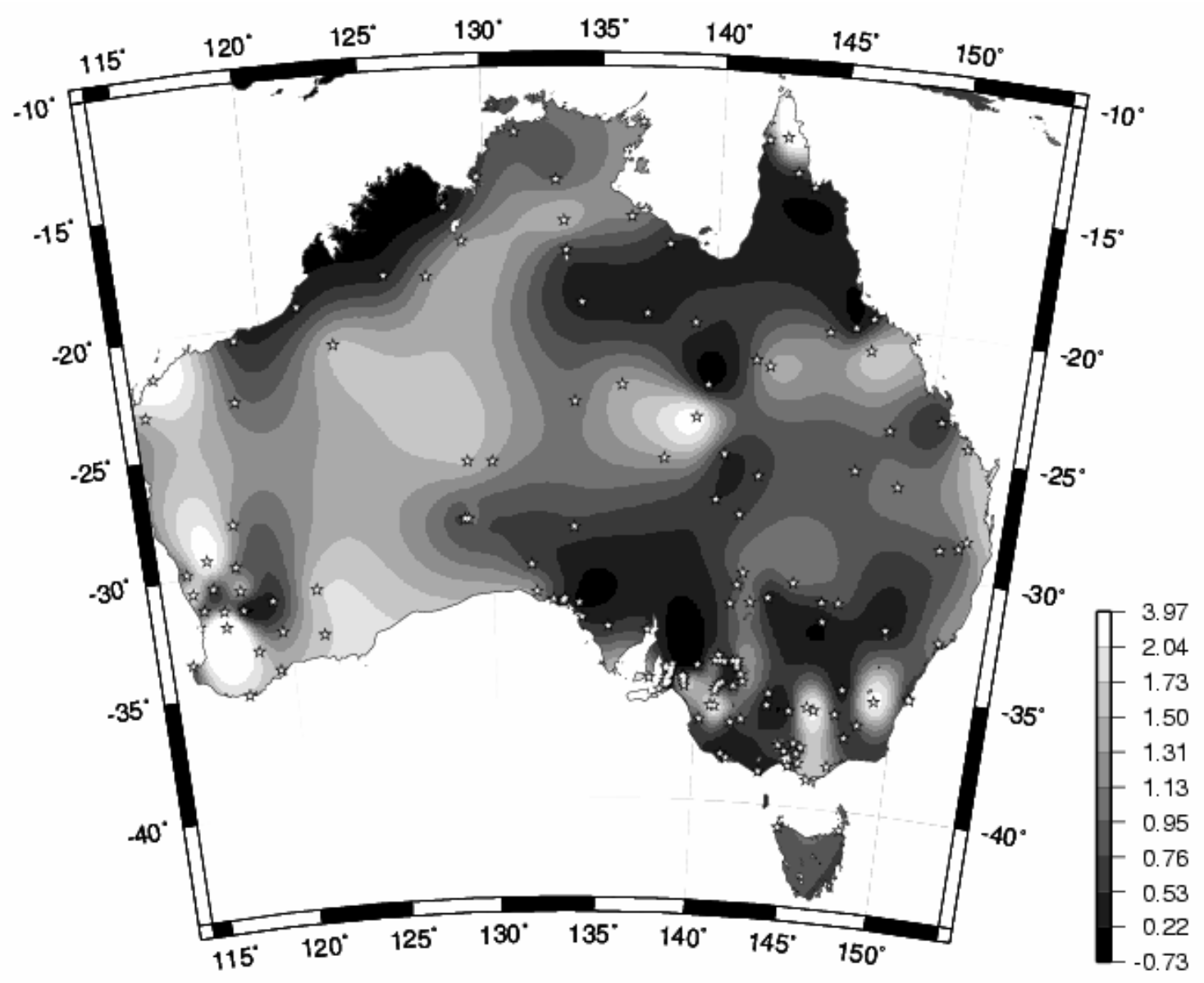

Figure 3. Interpolated contour map showing the magnitude of distortions across Australia, using the block shift transformation model with ICSM AGD66 to GDA94 transformation parameters compared to161 control points (units in metres). 


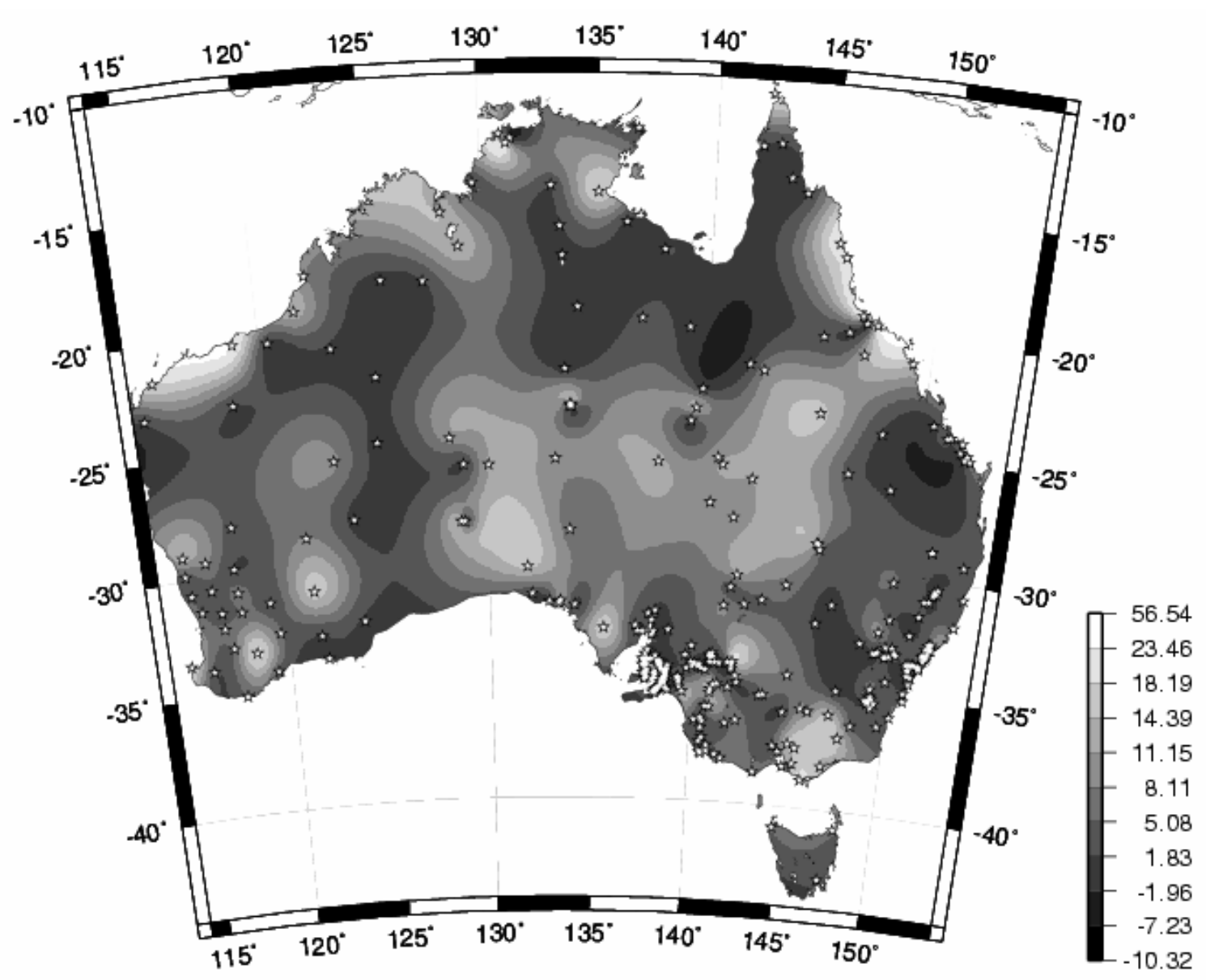

Figure 4. Interpolated contour map showing the magnitude of distortions across Australia, using the block shift transformation model with ICSM AGD84 to GDA94 transformation parameters compared to 327 control points (units in metres).

\section{Abridged Molodensky - new ICSM and old DMA parameters}

Being fundamentally a three-parameter transformation, the abridged Molodensky model (stated accuracy of 5m by ICSM (1997) and DMA (1987)) is concerned only with the shift in origin of the ellipsoids of the datums. As a result, accuracy is lost through the absence of the axial rotations, as well as the scale change in the seven-parameter transformation. Overall, the more recently derived ICSM parameters returned a better result than the older DMA parameters. Also, the DMA parameters were computed for AGD $<>$ WGS 84 transformations, and used fewer points. The means and standard deviations, respectively, using ICSM parameters were $1.583 \mathrm{~m}$ and $0.849 \mathrm{~m}$ for the AGD66 and $0.706 \mathrm{~m}$ and $0.426 \mathrm{~m}$ for the AGD84. The means and standard deviations 
using DMA parameters were $1.832 \mathrm{~m}$ and $1.273 \mathrm{~m}$ for the AGD66 and $1.338 \mathrm{~m}$ and $0.979 \mathrm{~m}$ for the AGD84.

What is noticeable is how much better the DMA parameters were for South Australia than for the other regions, in particular on the AGD84 (Table 6 and Figure 8). This is due to the aforementioned presence of a parameter bias combining with the large number of points being used in the transformation, particularly over South Australia. Table 5 shows that this bias is not as strong on the AGD66 because fewer points were used. Figure 8 also reveals a distinct tapering pattern in the positional differences of the observed and transformed points, moving away from South Australia and southeastern Australia. This demonstrates the spatial distribution of the points used in the DMA parameter estimation, these points favouring South Australia and south-eastern Australia then becoming sparser as they move away from these regions. Figure 7, while not as tapered, reveals a similar bias for the South Australia and south-eastern Australia regions as used by ICSM. 


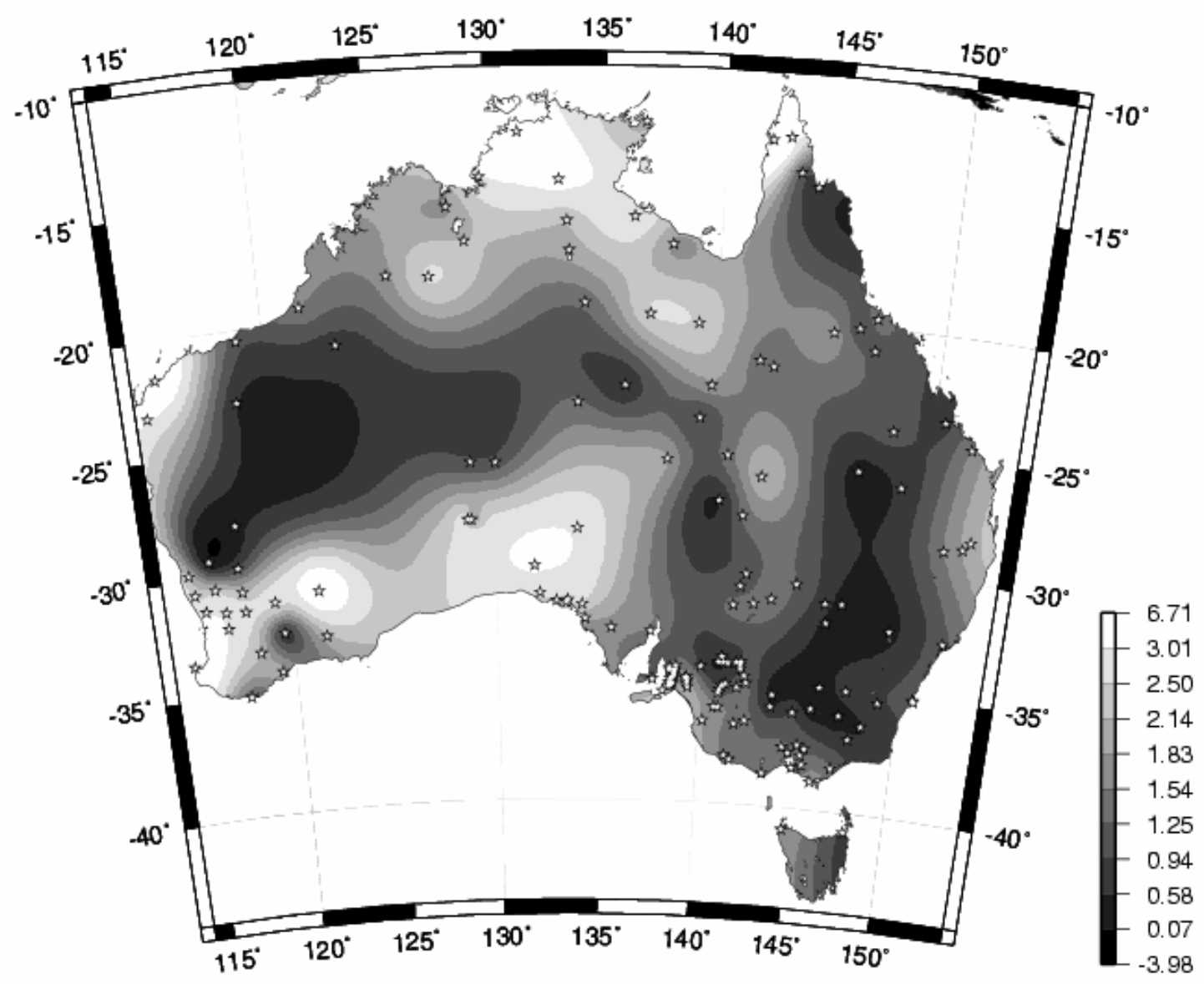

Figure 5. Interpolated contour map showing the magnitude of the distortions across Australia, using the abridged Molodensky transformation model with ICSM AGD66 to GDA94 transformation parameters compared to 161 control points (units in metres). 


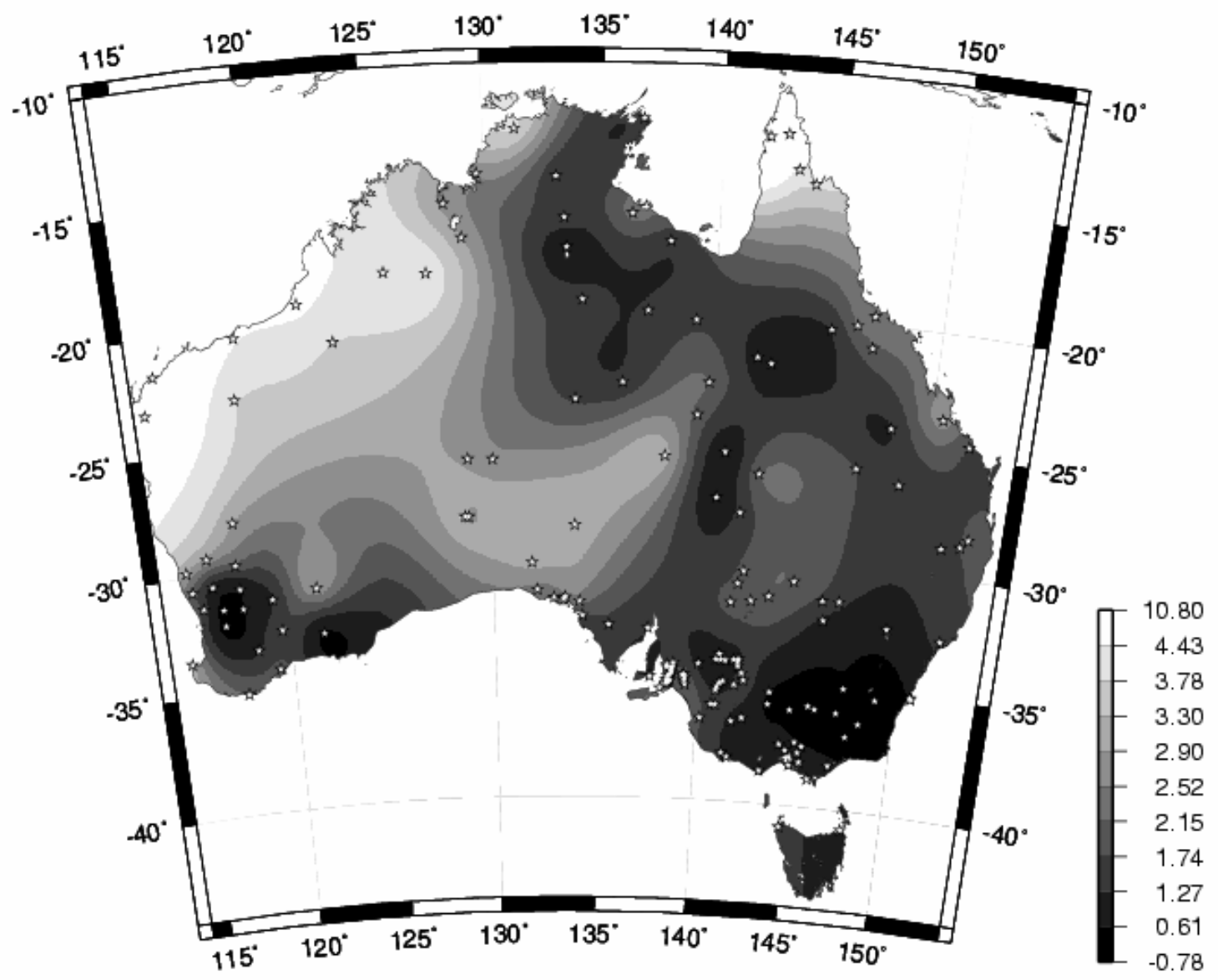

Figure 6. Interpolated contour map showing the magnitude of the distortions across Australia, using the abridged Molodensky transformation model with DMA AGD66 to WGS84 transformation parameters compared to 161 control points (units in metres). 


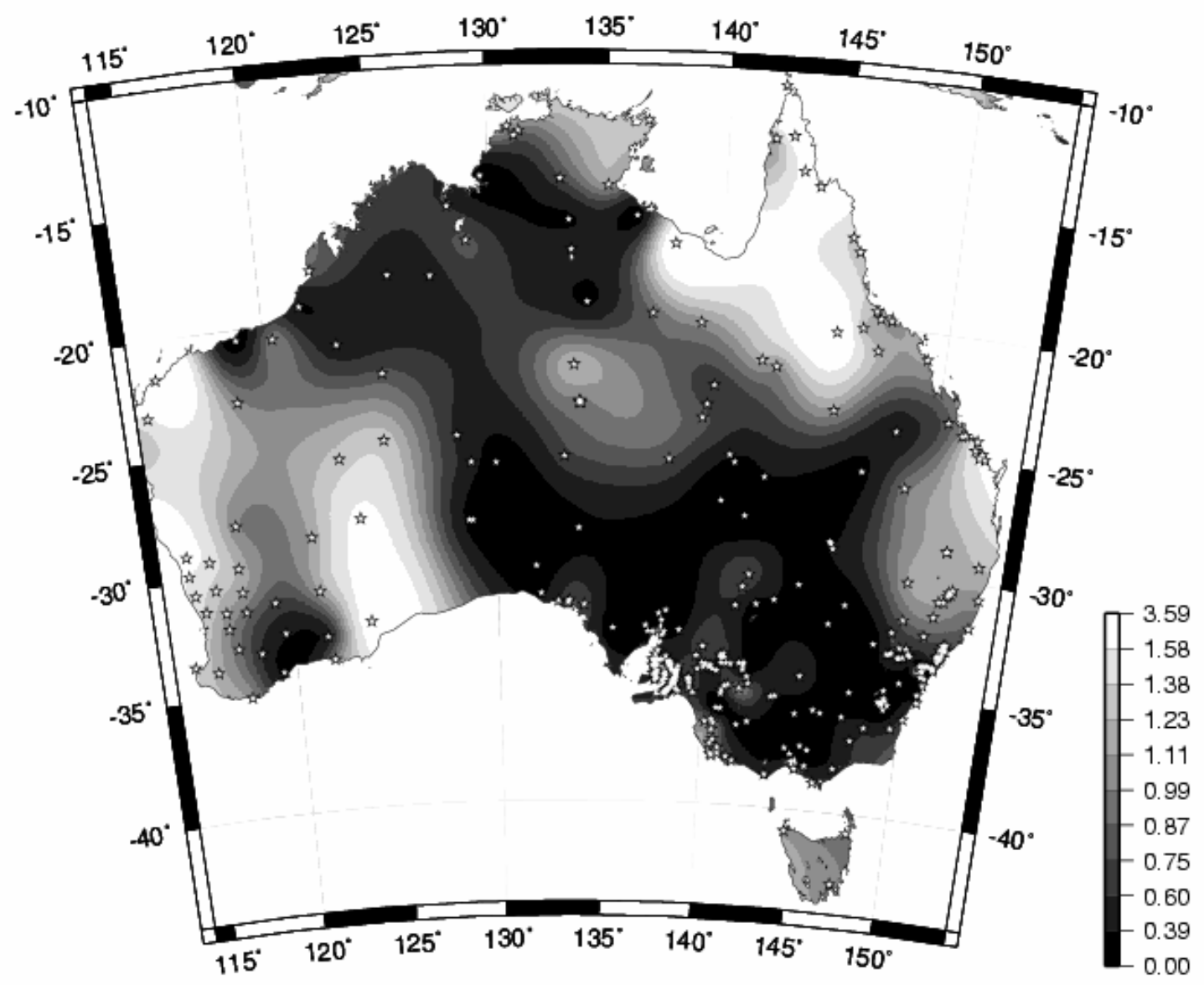

Figure 7. Interpolated contour map showing the magnitude of the distortions across Australia, using the abridged Molodensky transformation model with ICSM AGD84 to GDA94 transformation parameters compared to 327 control points (units in metres). 


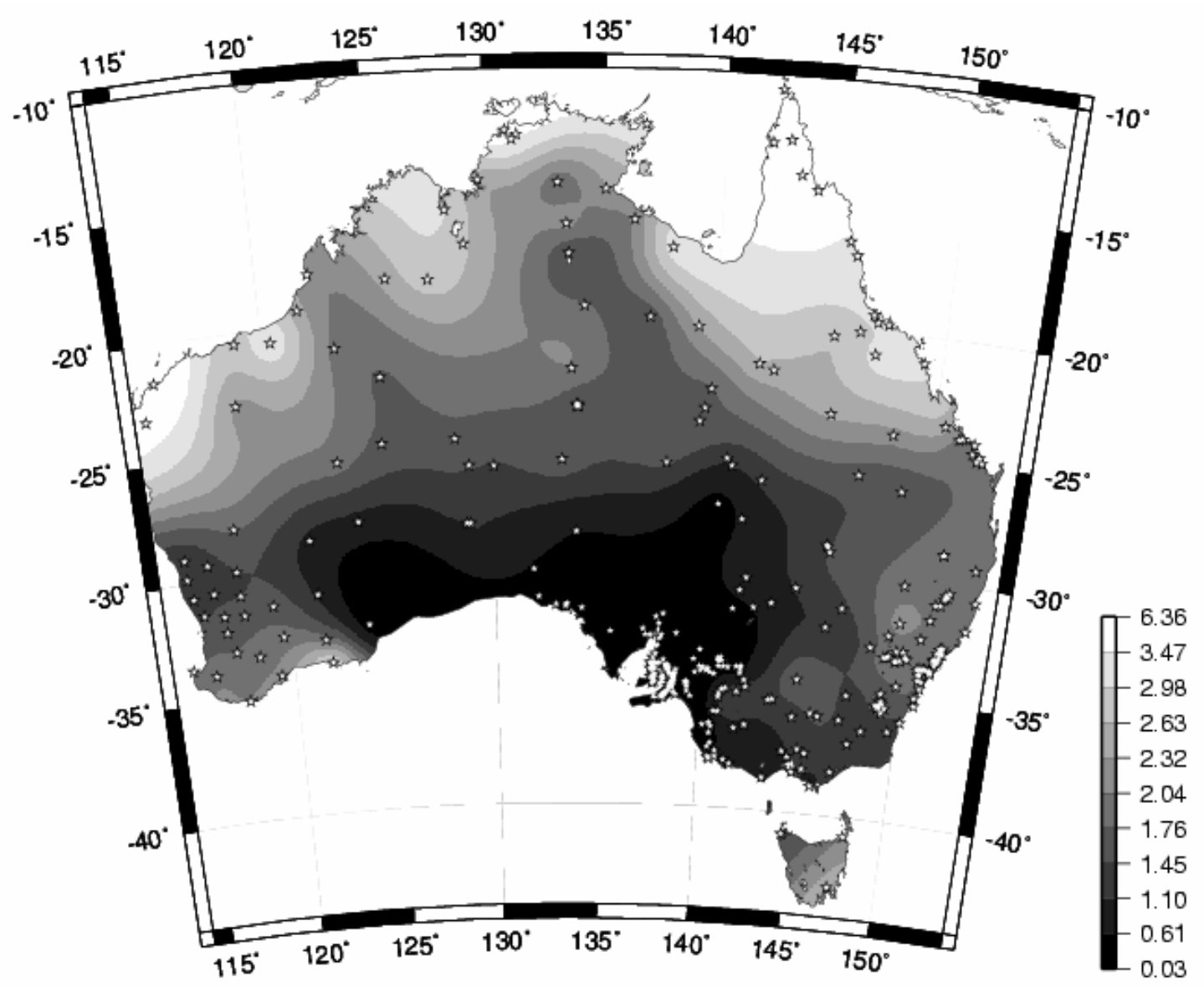

Figure 8. Interpolated contour map showing the magnitude of the distortions across Australia, using the abridged Molodensky transformation model with DMA AGD84 to WGS84 transformation parameters compared to 327 control points (units in metres).

\section{Standard Molodensky - old DMA parameters}

The standard Molodensky transformation model using DMA parameters produced nearidentical results to the abridged Molodensky (DMA) for both the AGD66 and AGD84. This was expected, as the standard model differs from the abridged only in that it uses the ellipsoidal height (h) in the algorithm. As mentioned earlier, the omission of the spheroidal height from the standard Molodensky formulae causes an error that is generally less than the accuracy of the transformation, especially for low-order datasets (e.g., Steed, 1995). 


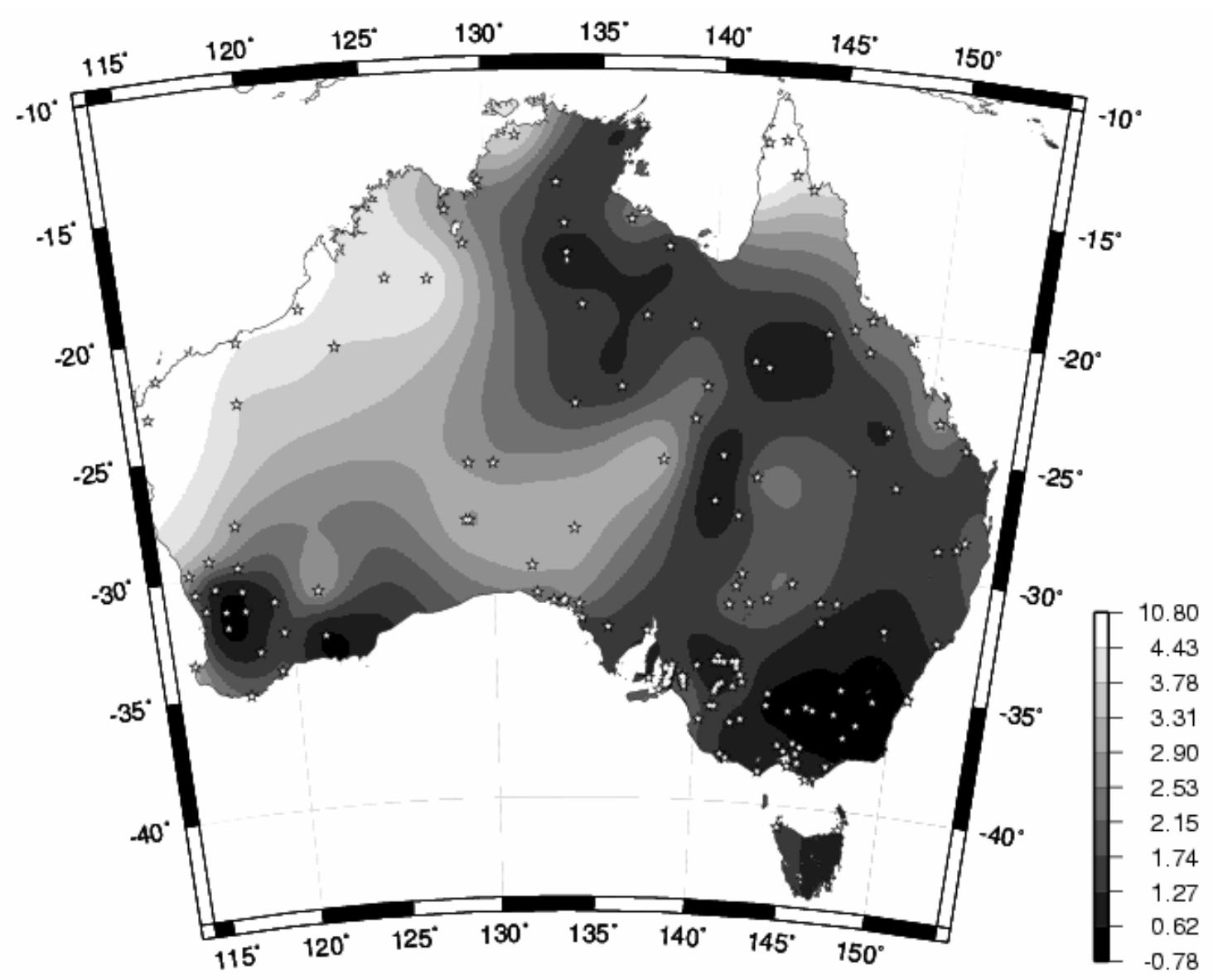

Figure 9. Interpolated contour map showing the magnitude of distortions across Australia, using the standard Molodensky transformation model with DMA AGD66 to WGS84 transformation parameters compared to 161 control points (units in metres). 


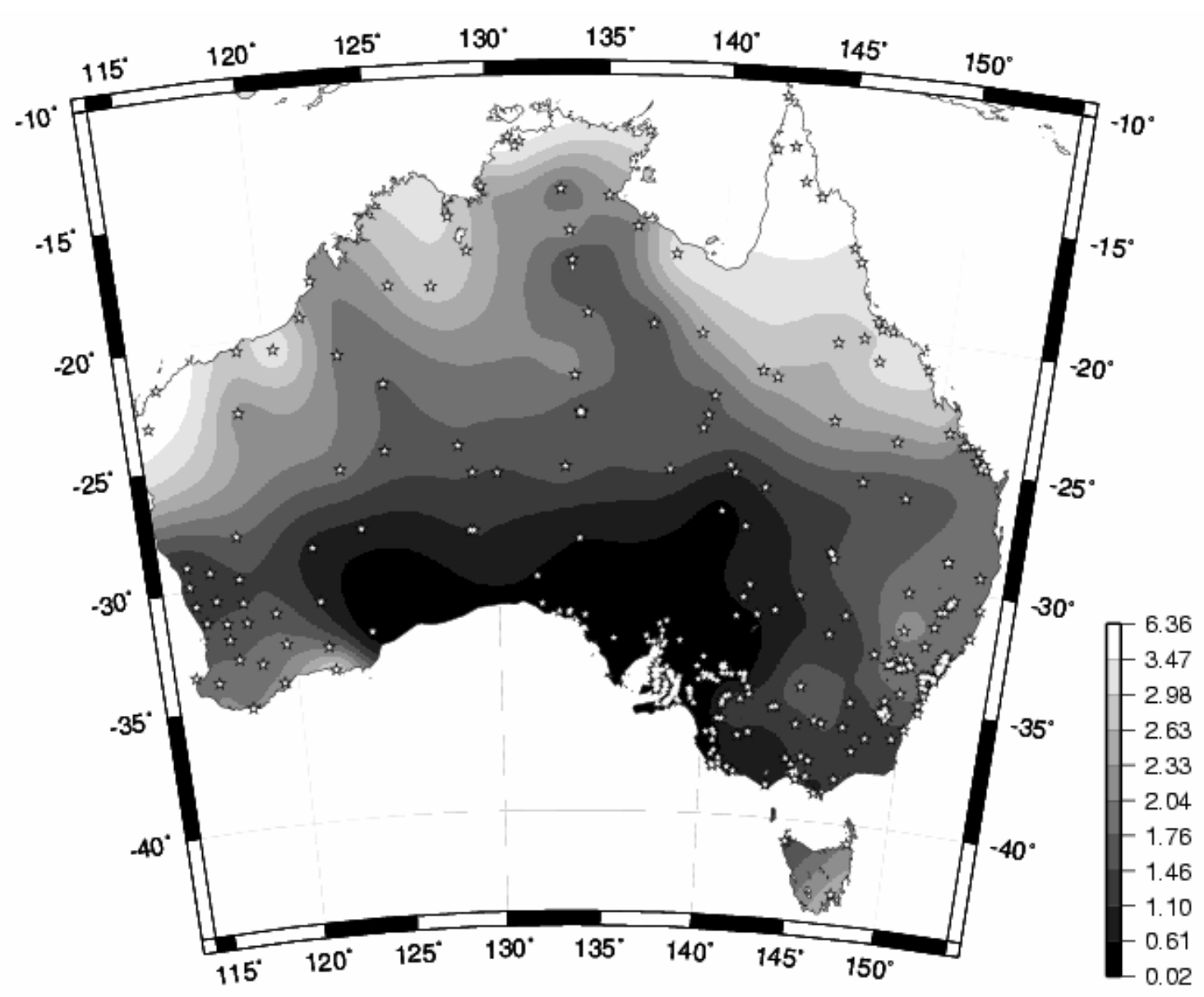

Figure 10. Interpolated contour map showing the magnitude of distortions across Australia, using the standard Molodensky transformation model with DMA AGD84 to WGS84 transformation parameters compared to 327 control points (units in metres).

\section{Multiple Regression Equations - old DMA parameters}

As MREs, being a projective transformation, account for distortions between datums, this transformation model would be expected to be more accurate than the previously discussed conformal methods. However, the abridged Molodensky (ICSM) for the AGD84 and the block shift for the AGD66 were better. The reasons for this are because of the parameter biases discussed earlier, and also the fact that the MRE parameters were computed for transformations between the AGD and WGS84 (DMA, 1987), not the GDA94. Also, the fact that only 90 stations were used in the determination of the polynomials somewhat limits the performance of this method.

Nevertheless, with a respective mean and standard deviation of $1.312 \mathrm{~m}$ and $1.359 \mathrm{~m}$ for the AGD66, and $1.225 \mathrm{~m}$ and $0.503 \mathrm{~m}$ for the AGD84, the results appear 
compatible with the published accuracy $(2 \mathrm{~m})$. However, there is a maximum residual of nearly $11 \mathrm{~m}$ on the AGD66 occurs in Carnarvon, Western Australia. As can be seen in Figure 11, the area between Geraldton and Exmouth contains generally large errrors for the AGD66, most of which were minimised though not eliminated during the readjustment of this datum to form the AGD84 (Figure 12). It is likely that these points were extrapolated in the transformation, thus losing accuracy.

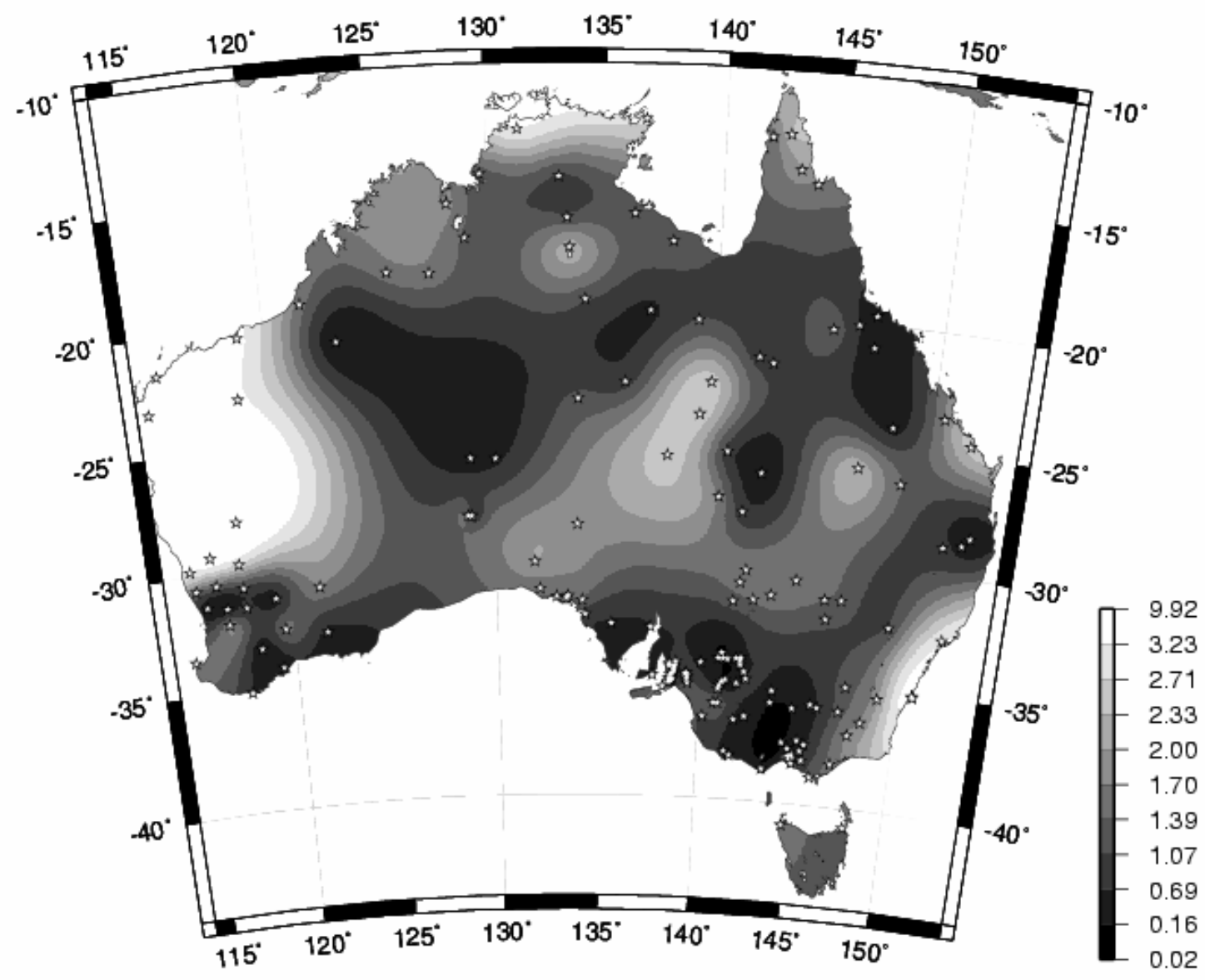

Figure 11. Interpolated contour map showing the magnitude of distortions across Australia, using the MRE transformation model with DMA AGD66 to WGS84 transformation parameters compared to 161 control points (units in metres). 


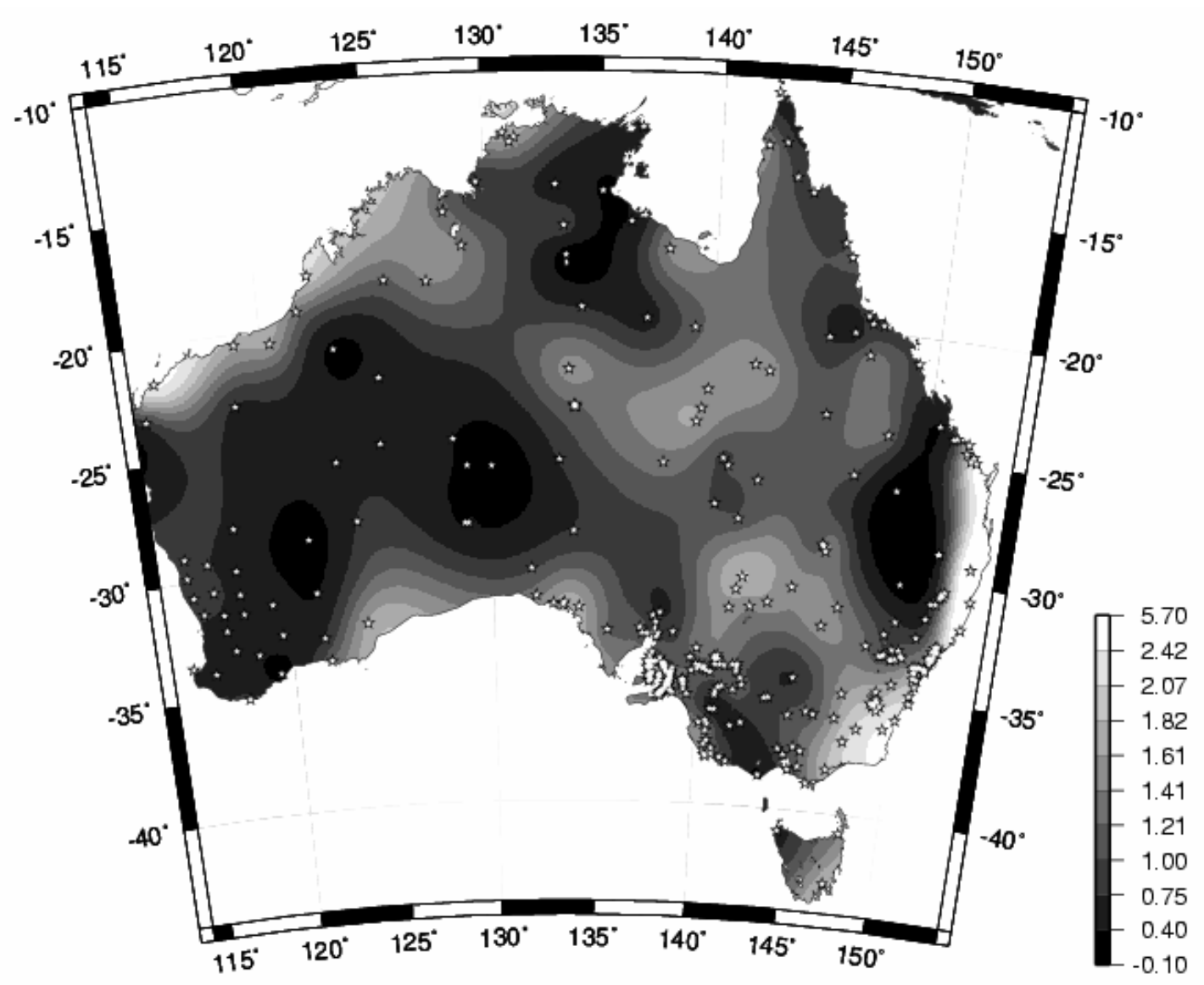

Figure 12. Interpolated contour map showing the magnitude of distortions across Australia, using the MRE transformation model with DMA AGD84 to WGS84 transformation parameters compared to 327 control points (units in metres).

\section{Three-Dimensional Similarity Transformation}

\section{New ICSM parameters}

The three-dimensional similarity method using ICSM parameters proved to be the next best. Because of the inconsistent nature of the AGD66, it is not possible to compute an accurate set of national AGD66 to GDA94 parameters. However, regional AGD66 to GDA94 parameters have been computed by ICSM, and these were used for the AGD66 States and Territories (New South Wales, Victoria, Tasmania, The Australian Capital Territory and the Northern Territory). This method produced a mean and standard deviation of $0.559 \mathrm{~m}$ and $0.378 \mathrm{~m}$ for the AGD66, and $0.438 \mathrm{~m}$ and $0.358 \mathrm{~m}$ for the AGD84 (published accuracy 1m). However, these results are influenced by the parameter bias discussed earlier and should be assumed as being slightly suspicious. 
The results for both datums are influenced by several factors, such as ratio of points per land area, number of remote points per region, distribution of points, and parameter biases. As mentioned earlier, a bias exists in the ICSM parameters for this transformation model. This bias can be clearly seen in Table 6 and Figure 14 for South Australia and south-eastern Australia. For the AGD66 (Regional) the results for data in south-eastern Australia were more than twice as good as the Northern Territory (Figure 13), while for the AGD84 the results for data in south-eastern Australia and South Australia were more than twice as good as Western Australia, the Northern Territory and Queensland.

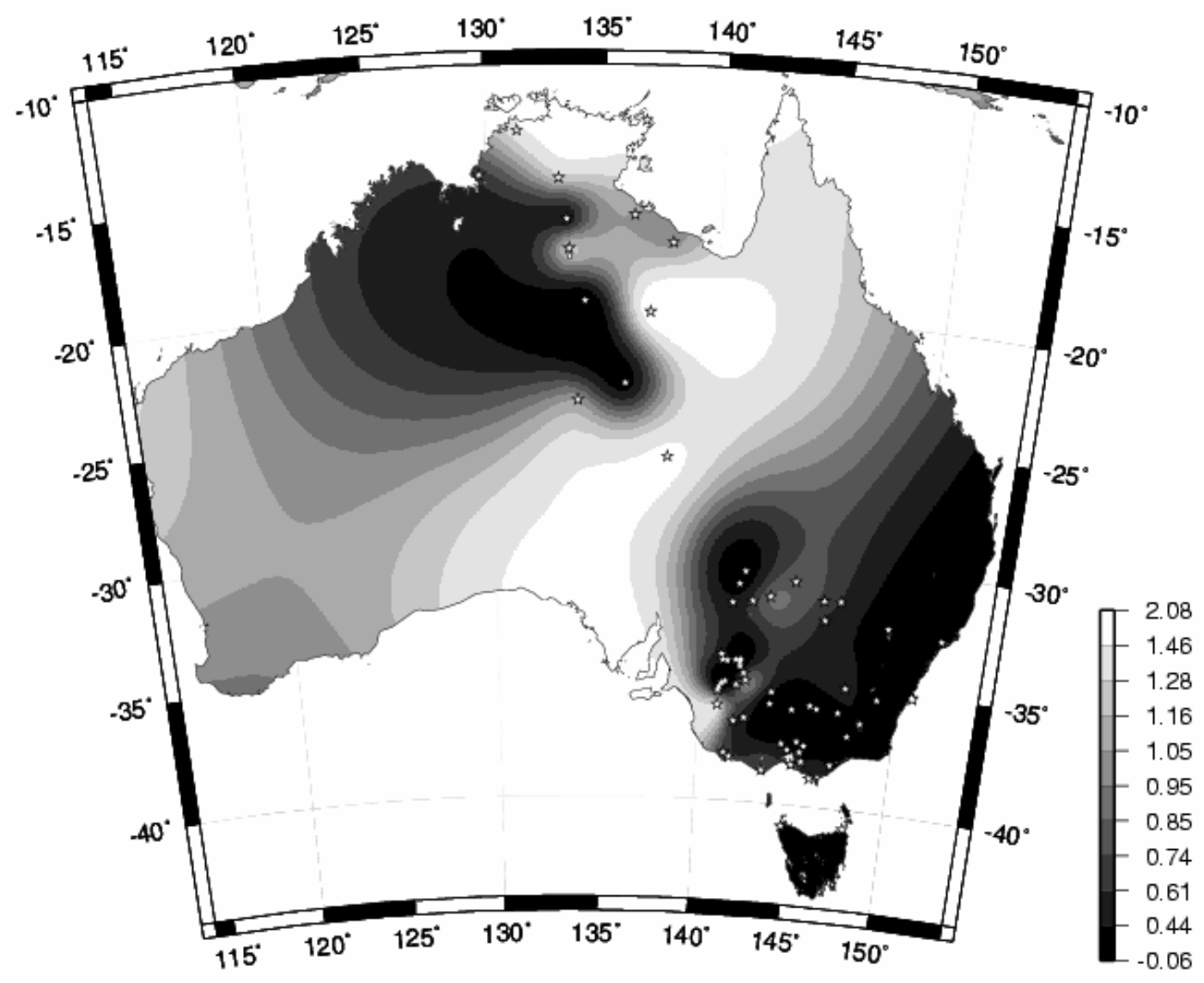

Figure 13. Interpolated contour map showing the magnitude of distortions across Australia, using the three-dimensional similarity transformation model with ICSM AGD66 to GDA94 (Regional) transformation parameters compared to 161 control points (units in metres). 


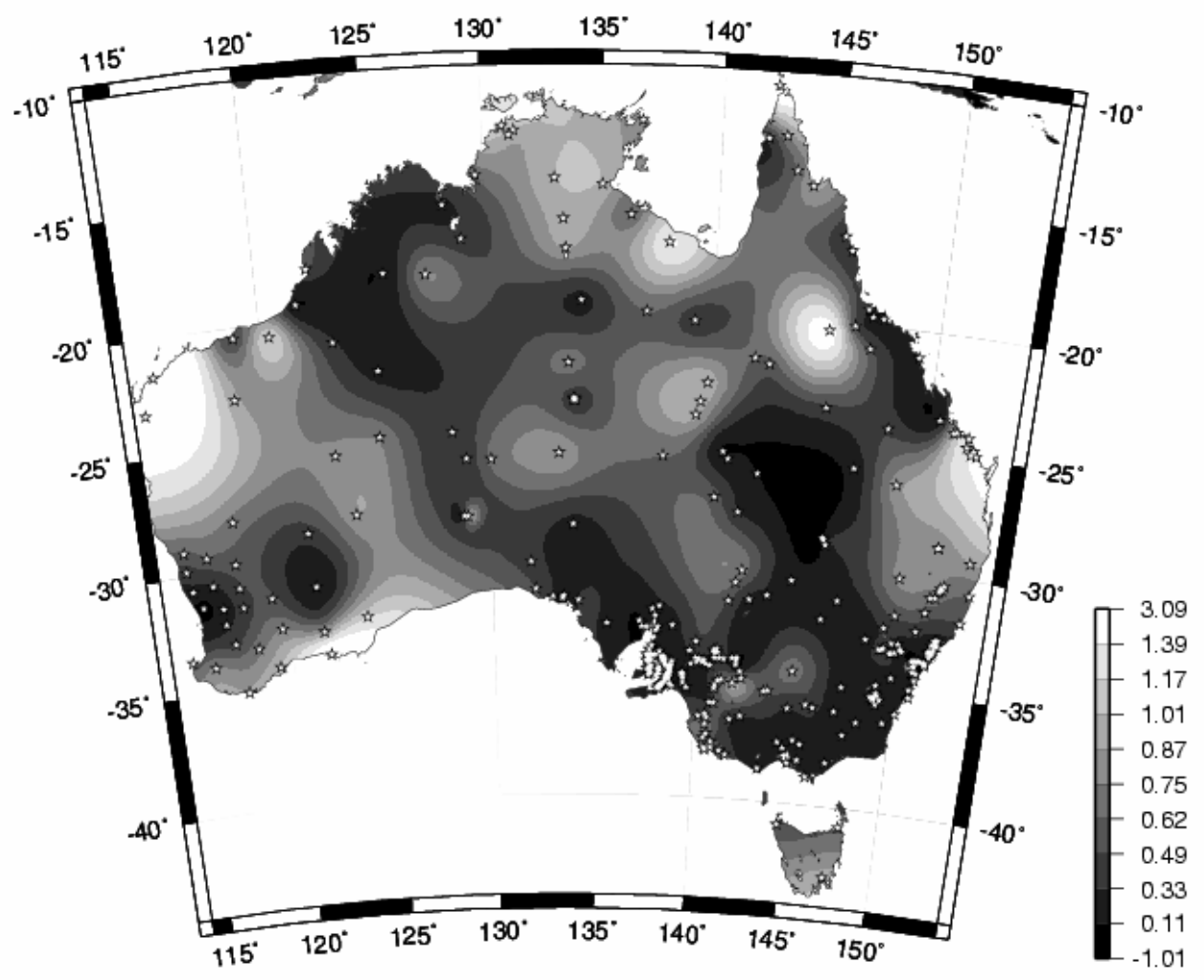

Figure 14. Interpolated contour map showing distortions across Australia, using the three-dimensional similarity transformation model with ICSM AGD84 to GDA94 transformation parameters compared to 327 control points (units in metres).

\section{Old Higgins parameters}

Higgins (1987) parameters for the three-dimensional similarity method were formulated for transformations between the AGD84 and WGS84 only, as opposed to the AGD66 and WGS84. Higgins used 90 well-distributed points across Australia (ibid.). As mentioned, these parameters were derived in 1987 using an indirect method. The results for the AGD84 using Higgins's parameters were homogenous throughout, reflecting uniformity in the point distribution and further demonstrating that the ICSM parameters are biased. Discounting this bias, the Higgins parameters generally compared favourably, with a mean and standard deviation of $0.819 \mathrm{~m}$ and $0.321 \mathrm{~m}$ respectively (Figure 15). 


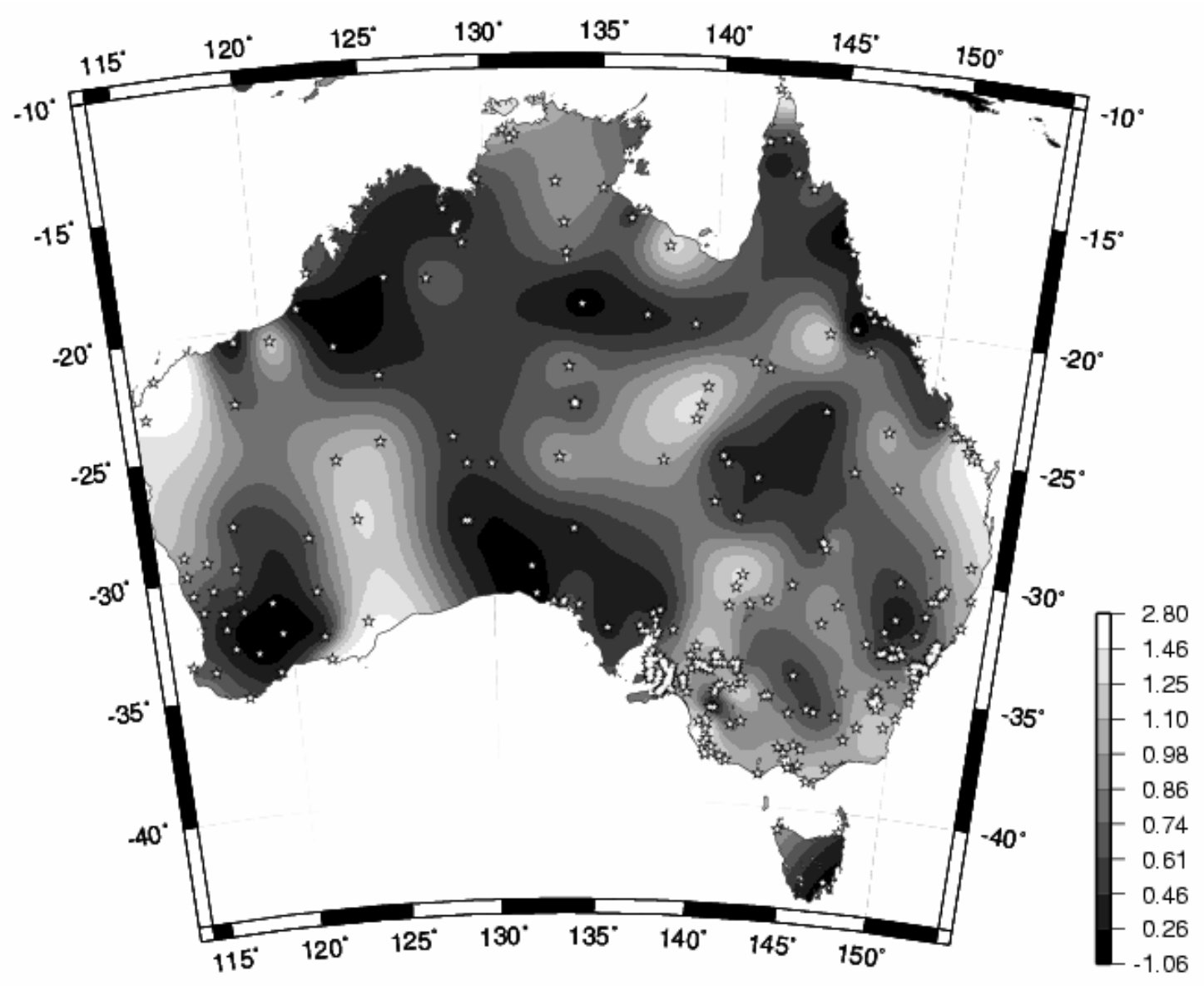

Figure 15. Interpolated contour map showing the magnitude of distortions across Australia, using the three-dimensional similarity transformation model with Higgins's AGD84 to WGS84 transformation parameters compared to 327 control points (units in metres).

\section{Grid Transformation - new ICSM data file}

The projective grid transformation method proved to be of highest accuracy, with means of $0.121 \mathrm{~m}$ and $0.097 \mathrm{~m}$ and standard deviations of $0.248 \mathrm{~m}$ and $0.208 \mathrm{~m}$ for the AGD66 and AGD84, respectively (published accuracy $10 \mathrm{~cm}$ or better). This was expected, as this method corrects for distortions that exist between the observed coordinates and those being transformed. Tables 7 and 8 show the statistics of the distortion correction accuracies for the nearest four surrounding grid nodes for transformed test points. It is to be emphasised that they represent the correction accuracy, not the correction itself, for that geographical region (Collier, 2002). These accuracies are reflective of the consistency or inconsistency of the local distortions, i.e., regions where dis- 
tortions are uniform can be modelled more accurately than regions where distortions are non-uniform. However, the uniform or non-uniform behaviour of distortions can be controlled to a great extent by grid-node spacing. Small grid-node spacing isolates distortion groups, which allows them to be modelled more rigorously, whereas large gridnode spacing tends to generalise the distortions and so accuracy is lost.

Thus, the reliability of the distortion corrections for a given region is shown by their correction accuracies. Tables 7 and 8 also show that the distortion corrections for the AGD84 are, on average, nearly twice as reliable than for the AGD66, for these data sets at least. This is partly because the distortions on the AGD84 are smaller and fewer, it being an improvement of the AGD66, and partly because of the smaller grid-node spacing of 3' (5.6km) over a large area (Western Australia, South Australia and Queensland) on the AGD84 as opposed to 9' $(16.7 \mathrm{~km})$ on the AGD66 for the same area.

Table 7. Statistics of grid-node correction accuracies for 161 AGD66 ground stations (units in metres).

\begin{tabular}{|l|c|c|c|c|c|c|}
\hline Region & $\mathrm{N}$ & Sum Lat & Sum Long & Av Lat & Av Long & Best \\
\hline WA & 34 & 5.15 & 4.4 & 0.15 & 0.13 & 3 \\
\hline SA & 40 & 3.7 & 3.95 & 0.09 & 0.10 & 2 \\
\hline QLD & 24 & 4.3 & 4.1 & 0.18 & 0.17 & 5 \\
\hline NT & 12 & 1.85 & 1.65 & 0.15 & 0.04 & 4 \\
\hline Nsw/Vic/Tas & 51 & 3.25 & 3.55 & 0.06 & 0.07 & 1 \\
\hline Total & 161 & & & & & \\
\hline
\end{tabular}

Table 8. Statistics of grid-node correction accuracies for 192 AGD84 ground stations (units in metres).

\begin{tabular}{|l|c|c|c|c|c|c|}
\hline Region & $\mathrm{N}$ & Sum Lat & Sum Long & Av Lat & Av Long & Best \\
\hline WA & 46 & 2.45 & 2.45 & 0.05 & 0.05 & 1 \\
\hline SA & 107 & 6.15 & 5.8 & 0.06 & 0.05 & 2 \\
\hline QLD & 39 & 3.95 & 4.1 & 0.10 & 0.11 & 3 \\
\hline Total & 192 & & & & & \\
\hline
\end{tabular}


By comparing Figures 16 and 17, it is interesting to note that in South Australia, the mean and standard deviation for the AGD66 (0.098 $\mathrm{m}$ and $0.114 \mathrm{~m})$ are better than for the AGD84 (0.121 $\mathrm{m}$ and $0.206 \mathrm{~m})$. The reason for this is because of a dozen or so largely distorted points on the Yorke Peninsula that were included in the AGD84 data set, but not in the AGD66. Because this is a narrow strip of land, the linear relationship of points does not lend itself well to least squares collocation. Hence poor transformation parameter/distortion modelling is the result.

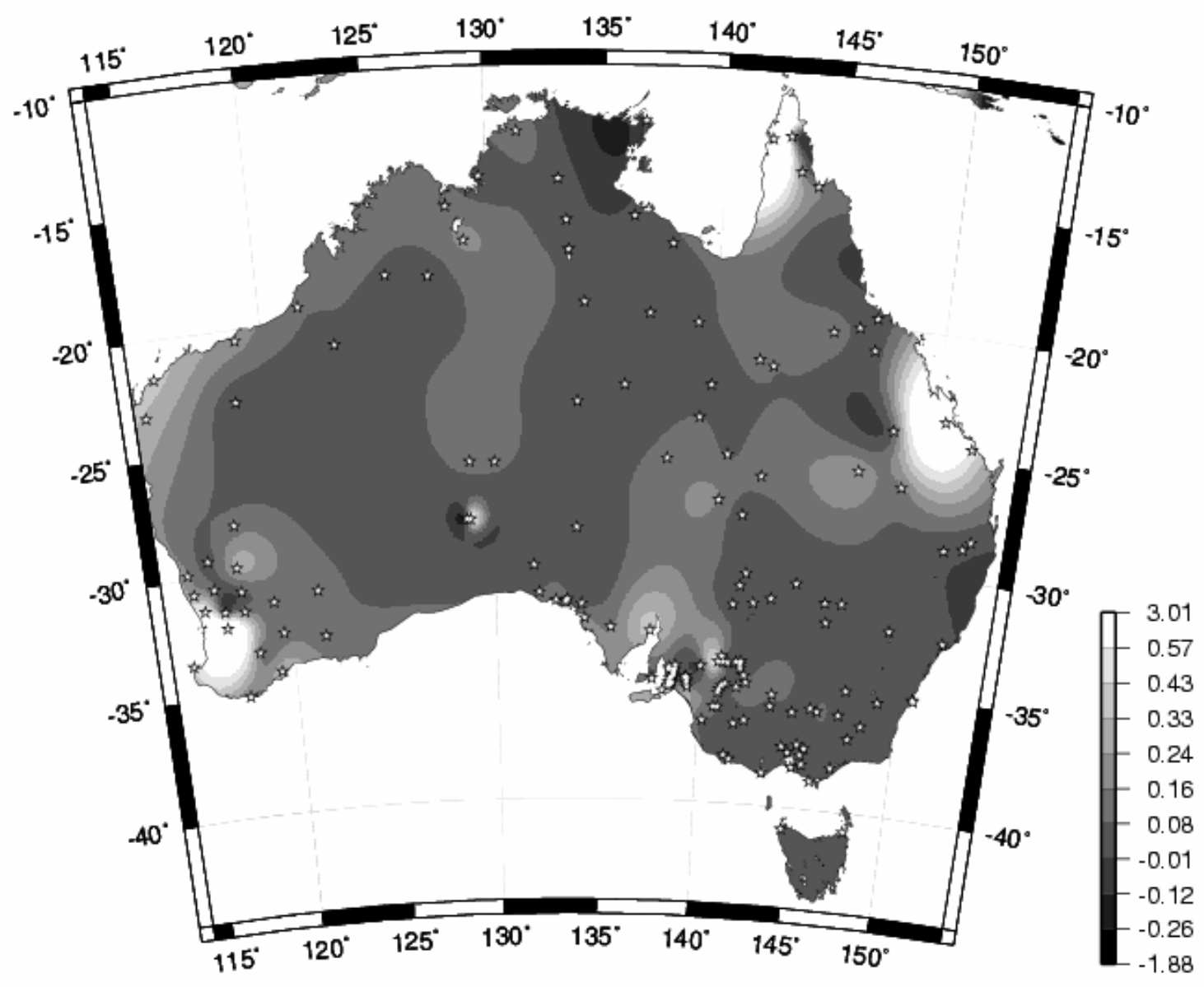

Figure 16. Interpolated contour map showing the magnitude of distortions across Australia, using the grid-file transformation model with ICSM A66 National (09-2001) AGD66 to GDA94 transformation parameters compared to 161 control points (units in metres). 


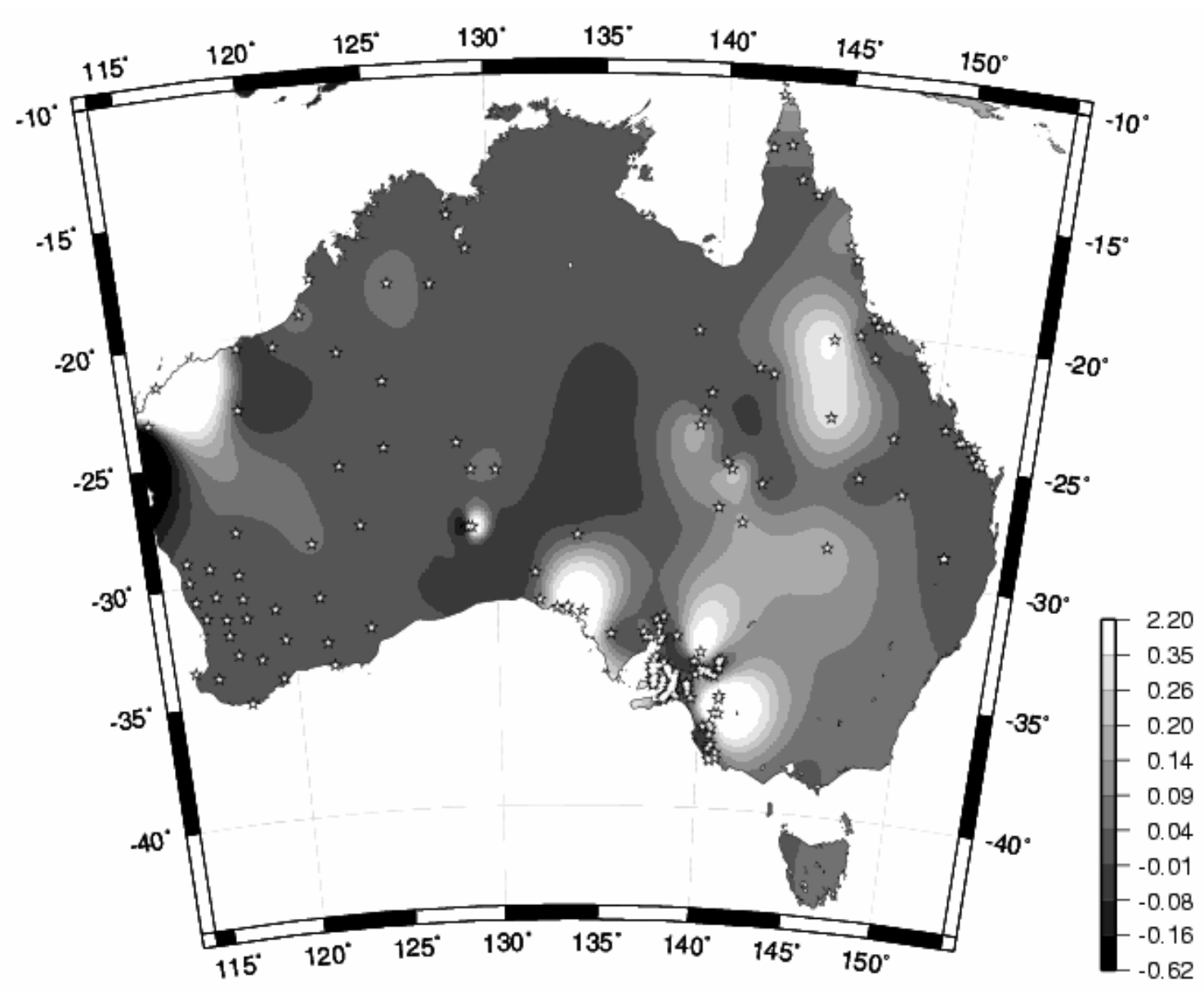

Figure 17. Interpolated contour map showing the magnitude of distortions across Australia, using the grid-file transformation model with ICSM National 84 (07-2001) AGD84 to GDA94 transformation parameters compared to 327 control points (units in metres).

\section{AUXILIARY CONSIDERATIONS}

Collier (2002) produced preliminary national distortion grids for the grid transformation method before the final ones were released. This is because fine adjustments were needed at State/Territory boundaries to correct poorly transformed points (Collier, 2002). The National 84 preliminary grid (02-07-2001) was deemed acceptable and so was not changed. However, small changes were made to the National A66 preliminary grid (29-06-2001) to produce the final distortion grid (13-09-2001). The difference between the preliminary and final A66 National distortion grids is in the vicinity of a few millimetres generally (Table 9). No improvements were made to the National 84 distortion grid; hence it is the Final National 84 distortion grid. 
Table 9. Comparison of descriptive statistics for Preliminary (29-06-01) and Final (1309-01) AGD66 National to GDA94 grid transformations using the Geod 3.30 transformation software (units in metres)

\begin{tabular}{|l|c|c|c|c|c|c|c|c|c|c|c|c|}
\hline \multirow{2}{*}{ Region } & \multicolumn{2}{|c|}{$\begin{array}{c}\text { WA } \\
(34)\end{array}$} & \multicolumn{2}{c|}{$\begin{array}{c}\text { SA } \\
(40)\end{array}$} & \multicolumn{2}{c|}{$\begin{array}{c}\text { QLD } \\
(24)\end{array}$} & \multicolumn{2}{c|}{$\begin{array}{c}\text { NT } \\
(12)\end{array}$} & \multicolumn{2}{c|}{$\begin{array}{c}\text { Nsw/Vic/Tas } \\
(51)\end{array}$} & \multicolumn{2}{c|}{$\begin{array}{c}\text { National } \\
(161)\end{array}$} \\
\cline { 2 - 13 } & Pre & Final & Pre & Final & Pre & Final & Pre & Final & Pre & Final & Pre & Final \\
\hline Min & 0.004 & 0.004 & 0.008 & 0.008 & 0.008 & 0.013 & 0.007 & 0.013 & 0.004 & 0.004 & 0.004 & 0.004 \\
\hline Max & 1.150 & 1.150 & 0.426 & 0.505 & 2.306 & 2.344 & 0.183 & 0.149 & 0.237 & 0.240 & 2.306 & 2.344 \\
\hline Std & 0.225 & 0.225 & 0.114 & 0.124 & 0.518 & 0.531 & 0.053 & 0.039 & 0.046 & 0.046 & 0.259 & 0.251 \\
\hline Mean & 0.207 & 0.207 & 0.196 & 0.106 & 0.290 & 0.273 & 0.054 & 0.052 & 0.045 & 0.040 & 0.134 & 0.128 \\
\hline
\end{tabular}

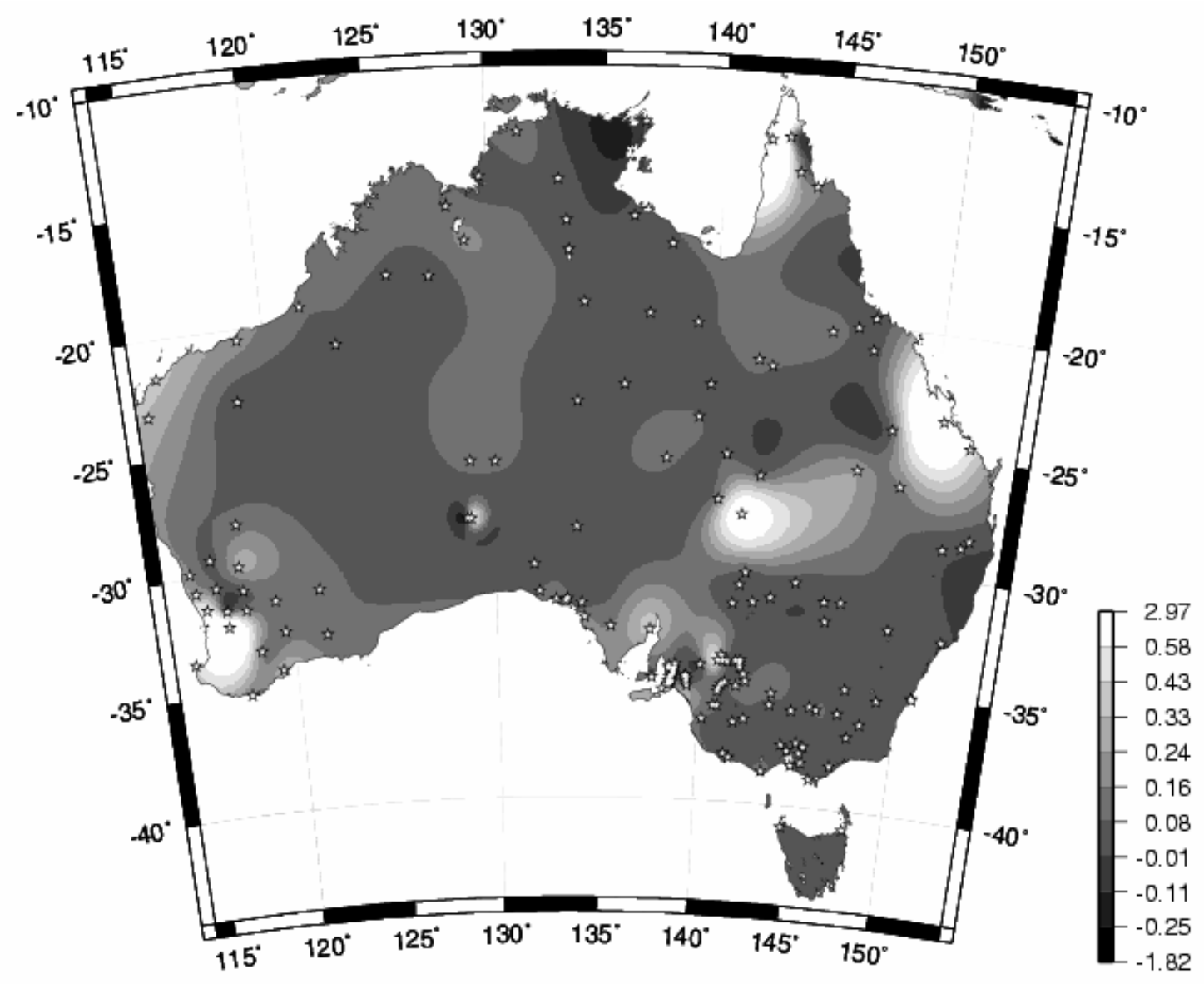


Figure 18. Interpolated contour map showing the magnitude of distortions across Australia, using the Preliminary grid transformation model with ICSM A66 National (2906-2001) AGD66 to GDA94 data compared to 161 control points (units in metres).

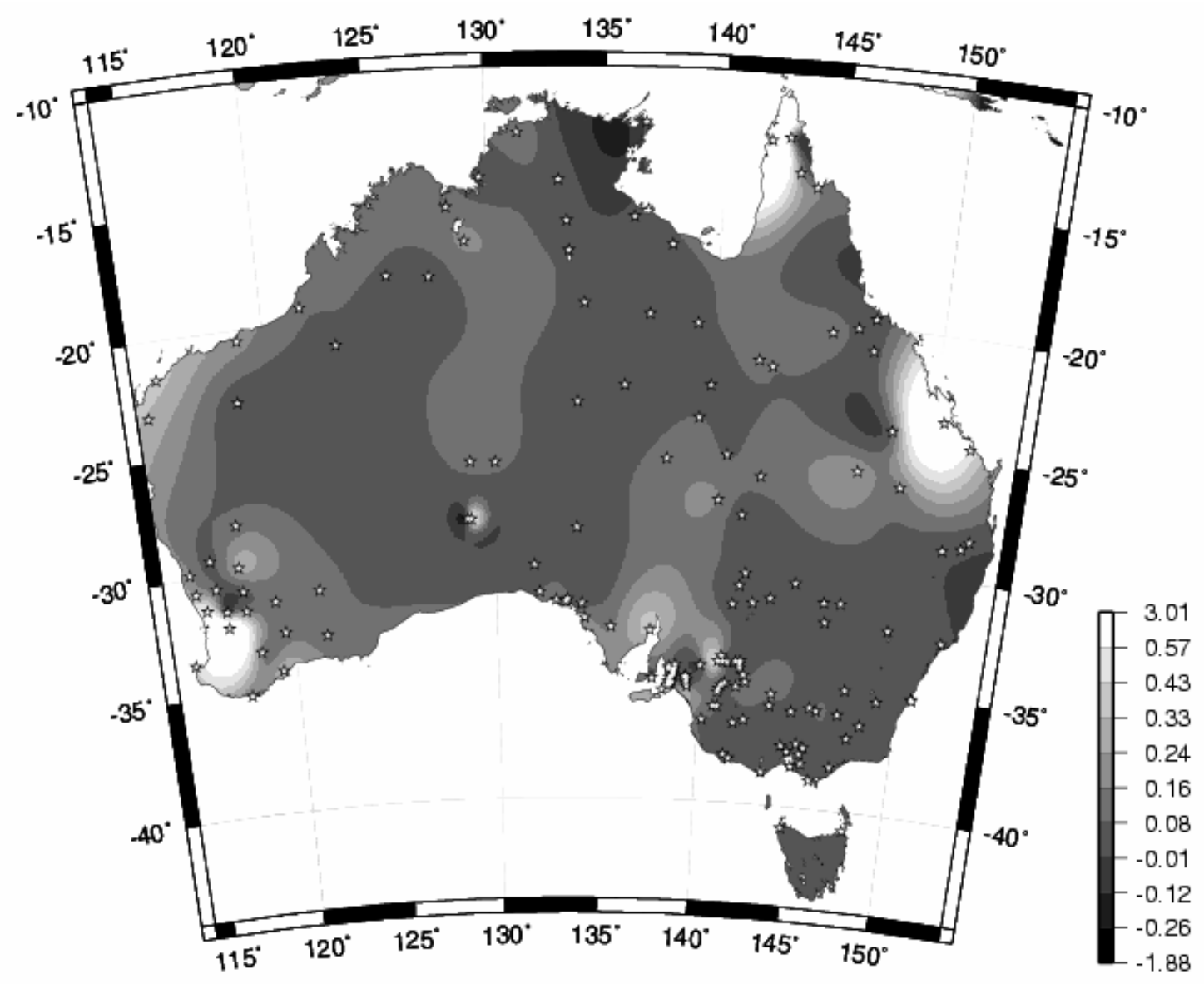

Figure 19. Interpolated contour map showing the magnitude of distortions across Australia, using the Final grid-file transformation model with ICSM A66 National (02-072001) AGD66 to GDA94 data compared to 161 control points (units in metres).

ICSM first produced distortion grids for each State and Territory before joining them together to produce the A66 National and National 84 distortion grids (Collier, 2002). The difference between the local and national distortion grids is in the vicinity of a few millimetres on the AGD66 and sub-millimetre on the AGD84 (Tables 10 and 11). 
Table 10. Comparison of descriptive statistics between State and National AGD66 to GDA94 distortion grids, using the Geod 3.30 transformation software (units in metres)

\begin{tabular}{|l|c|c|c|c|}
\hline \multirow{2}{*}{ Region } & \multicolumn{2}{|c|}{ NT (12) } & \multicolumn{2}{c|}{ Nsw/Vic/Tas (51) } \\
\cline { 2 - 5 } & State & National & State & National \\
\hline Gsb File & NT_1000 & A66 National (130901) & $\begin{array}{c}\text { A66 (State) 0600 } \\
\text { Tas_1098 }\end{array}$ & A66 National (130901) \\
\hline Min & 0.009 & 0.013 & 0.003 & 0.004 \\
\hline Max & 0.183 & 0.149 & 0.237 & 0.240 \\
\hline Std & 0.053 & 0.039 & 0.046 & 0.046 \\
\hline Mean & 0.058 & 0.052 & 0.041 & 0.040 \\
\hline
\end{tabular}

Table 11. Comparison of descriptive statistics between State and National AGD84 to GDA94 distortion grids, using the Geod 3.30 transformation software (units in metres)

\begin{tabular}{|l|c|c|c|c|c|c|}
\hline \multirow{2}{*}{ Region } & \multicolumn{2}{|c|}{ WA (46) } & \multicolumn{2}{c|}{ SA (107) } & \multicolumn{2}{c|}{ QLD (39) } \\
\cline { 2 - 7 } & State & National & State & National & State & National \\
\hline Gsb File & WA_0700 & $\begin{array}{c}\text { National 84 } \\
(020701)\end{array}$ & SA_0301 & $\begin{array}{c}\text { National 84 } \\
(020701)\end{array}$ & Qld_0900 & $\begin{array}{c}\text { National 84 } \\
(020701)\end{array}$ \\
\hline Min & 0.000 & 0.000 & 0.003 & 0.003 & 0.006 & 0.006 \\
\hline Max & 1.860 & 1.860 & 0.899 & 0.899 & 0.368 & 0.368 \\
\hline Std & 0.282 & 0.282 & 0.220 & 0.220 & 0.084 & 0.084 \\
\hline Mean & 0.065 & 0.065 & 0.130 & 0.130 & 0.072 & 0.072 \\
\hline
\end{tabular}

Software programs have been created to perform National AGD66/84<>GDA94 grid transformations, and are available free to users. These programs are simple to use and provide a range of facilities useful to those working in the surveying, cartography and GIS areas. This software and national distortion grids for the AGD66 and AGD84 are available for free download from the ICSM web site at http://www.icsm.gov.au/icsm/gda/gdatm/index.html. Tables 12 and 13 show how each program differs little from the other in terms of transformation results. 
Table 12. Descriptive statistics of the positional differences between transformed GDA94 (from AGD66) coordinates and observed GDA94 coordinates at 161 points across Australia using the grid transformation method and A66 National distortion grid (units in metres).

\begin{tabular}{|c|c|c|c|c|c|c|c|c|c|c|c|c|c|c|}
\hline \multicolumn{15}{|c|}{ AGD66 - GDA94 } \\
\hline \multicolumn{2}{|c|}{ Region } & & \multicolumn{2}{|c|}{ WA } & \multicolumn{2}{|c|}{ SA } & \multicolumn{2}{|c|}{ QLD } & \multicolumn{2}{|c|}{$\begin{array}{c}\text { Nsw/Vic/ } \\
\text { Tas }\end{array}$} & \multicolumn{2}{|c|}{ NT } & \multicolumn{2}{|c|}{ National } \\
\hline Lat & Long & & $\begin{array}{l}-14^{\circ} \\
-35^{\circ} \\
\end{array}$ & $\begin{array}{l}113^{\circ} \\
129^{\circ}\end{array}$ & $\begin{array}{l}-26^{\circ} \\
-36^{\circ} \\
\end{array}$ & $\begin{array}{l}130^{\circ} \\
140^{\circ}\end{array}$ & $\begin{array}{l}-12^{\circ} \\
-28^{\circ} \\
\end{array}$ & $\begin{array}{l}139^{\circ} \\
152^{\circ} \\
\end{array}$ & $\begin{array}{l}-30^{\circ} \\
-40^{\circ} \\
\end{array}$ & $\begin{array}{l}141^{\circ} \\
151^{\circ} \\
\end{array}$ & $\begin{array}{l}-12^{\circ} \\
-25^{\circ} \\
\end{array}$ & $\begin{array}{l}131^{\circ} \\
137^{\circ} \\
\end{array}$ & $\begin{array}{l}-12^{\circ} \\
-40^{\circ} \\
\end{array}$ & $\begin{array}{l}113^{\circ} \\
152^{\circ} \\
\end{array}$ \\
\hline \multicolumn{2}{|c|}{$\begin{array}{l}\text { Distortion } \\
\text { grid }\end{array}$} & & \multicolumn{2}{|c|}{$\begin{array}{l}\text { A66 Na- } \\
\text { tional } \\
(13-09-01)\end{array}$} & \multicolumn{2}{|c|}{$\begin{array}{l}\text { A66 Na- } \\
\text { tional } \\
(13-09-01)\end{array}$} & \multicolumn{2}{|c|}{$\begin{array}{l}\text { A66 Na- } \\
\text { tional } \\
(13-09-01)\end{array}$} & \multicolumn{2}{|c|}{$\begin{array}{l}\text { A66 Na- } \\
\text { tional } \\
(13-09-01)\end{array}$} & \multicolumn{2}{|c|}{$\begin{array}{l}\text { A66 Na- } \\
\text { tional } \\
(13-09-01)\end{array}$} & \multicolumn{2}{|c|}{$\begin{array}{l}\text { A66 Na- } \\
\text { tional } \\
(13-09-01)\end{array}$} \\
\hline \multicolumn{2}{|c|}{ Grid Spacing } & & \multicolumn{2}{|c|}{$9^{\prime}$} & \multicolumn{2}{|c|}{$9^{\prime}$} & \multicolumn{2}{|c|}{$9^{\prime}$} & \multicolumn{2}{|c|}{$\begin{array}{l}1.8^{\prime} \text { (plus } \\
\text { sub-grids of } \\
54 ") * *\end{array}$} & \multicolumn{2}{|c|}{$9^{\prime}$} & & \\
\hline \multicolumn{2}{|c|}{ N Pts } & & \multicolumn{2}{|c|}{34} & \multicolumn{2}{|l|}{40} & \multicolumn{2}{|l|}{24} & \multicolumn{2}{|c|}{51} & \multicolumn{2}{|l|}{12} & \multicolumn{2}{|l|}{161} \\
\hline \multicolumn{2}{|c|}{$\begin{array}{l}\text { Areas to } \\
\text { watch }\end{array}$} & & \multicolumn{2}{|c|}{$\begin{array}{l}\text { (Wyndham, } \\
\text { Exmouth, } \\
\text { York, Es- } \\
\text { perance, } \\
\text { SA-NT- } \\
\text { Borders) }\end{array}$} & \multicolumn{2}{|c|}{$\begin{array}{l}\text { (Whyalla, } \\
\text { Adelaide, } \\
\text { Gt Aust } \\
\text { Bight, } \\
\text { Vic/Nsw- } \\
\text { Border) }\end{array}$} & $\begin{array}{l}\text { (Ca1 } \\
\text { Rom } \\
\text { Char } \\
\text { Rock } \\
\text { SA-H }\end{array}$ & $\begin{array}{l}\text { York, } \\
\text { ville, } \\
\text { amptn, } \\
\text { order) }\end{array}$ & $\begin{array}{l}\text { (Swa } \\
\text { Mildu } \\
\text { Qld/S } \\
\text {-Bord }\end{array}$ & $\begin{array}{l}\text { Hill, } \\
\text { a, } \\
\text { /Nsw } \\
\text { r) }\end{array}$ & $\begin{array}{l}\text { (Arnl } \\
\text { Land }\end{array}$ & & & \\
\hline Wor & $\mathrm{Pt} *$ & & $\begin{array}{l}1.150 \\
\text { (Yor }\end{array}$ & & $\begin{array}{l}0.513 \\
\text { (Vic) } \\
\text { A- B }\end{array}$ & $\begin{array}{l}\text { sw/S } \\
\text { der) }\end{array}$ & $\begin{array}{l}2.34 \\
\text { (Cap }\end{array}$ & York) & $\begin{array}{l}0.270 \\
\text { (Qld/ } \\
\text {-Bord }\end{array}$ & $\begin{array}{l}\text { A/Nsw } \\
\text { r) }\end{array}$ & $\begin{array}{l}0.151 \\
\text { (Arnl } \\
\text { land) }\end{array}$ & & $\begin{array}{l}2.34 \\
\text { (Cap } \\
\text { Qld) }\end{array}$ & York, \\
\hline GD & 2.0 & Min & & & & & & 08 & & & & & & 03 \\
\hline & & Max & & 49 & & & & 06 & & & & & & 06 \\
\hline & & Std & & 25 & & & & 46 & & & & & & 59 \\
\hline & & Mean & & & & & & 13 & & & & & & 34 \\
\hline GD & 2.0 & Min & & & & & & 08 & & & & & & 03 \\
\hline & & Max & & 49 & & & & 06 & & & & & & 06 \\
\hline & & Std & & 25 & & & & 46 & & & & & & 59 \\
\hline & & Mean & & 07 & & & & 13 & & & & & & 34 \\
\hline Geo & 3.30 & Min & & 04 & & & & 13 & & & & & & 04 \\
\hline & & $\operatorname{Max}$ & & 50 & & & & 44 & & & & & & 44 \\
\hline & & Std & & 25 & & & & 31 & & & & & & 51 \\
\hline & & Mean & & 07 & & & & 73 & & & & & & 28 \\
\hline
\end{tabular}

** Melbourne and Hobart (Collier, 2002). 
Table 13. Descriptive statistics of the differences between transformed GDA94 (from AGD84) coordinates and observed GDA94 coordinates at 192 points across Australia using the grid transformation method and National 84 distortion grid (units in metres).

\begin{tabular}{|c|c|c|c|c|c|c|c|c|c|c|}
\hline \multicolumn{11}{|c|}{ AGD84 - GDA94 } \\
\hline \multicolumn{2}{|c|}{ Region } & & \multicolumn{2}{|c|}{ WA } & \multicolumn{2}{|c|}{ SA } & \multicolumn{2}{|c|}{ QLD } & \multicolumn{2}{|c|}{ National } \\
\hline Lat & Long & & $\begin{array}{l}-15^{\circ} \\
-35^{\circ}\end{array}$ & $\begin{array}{l}113^{\circ} \\
129^{\circ}\end{array}$ & $\begin{array}{l}-26^{\circ} \\
-38^{\circ}\end{array}$ & $\begin{array}{l}130^{\circ} \\
140^{\circ}\end{array}$ & $\begin{array}{l}-12^{\circ} \\
-29^{\circ}\end{array}$ & $\begin{array}{l}139^{\circ} \\
152^{\circ}\end{array}$ & $\begin{array}{l}-12^{\circ} \\
-38^{\circ}\end{array}$ & $\begin{array}{l}113^{\circ} \\
152^{\circ}\end{array}$ \\
\hline \multicolumn{2}{|c|}{ Gsb file } & & \multicolumn{2}{|c|}{$\begin{array}{l}\text { National } 84 \\
(02-07-01)\end{array}$} & \multicolumn{2}{|c|}{$\begin{array}{l}\text { National } 84 \\
(02-07-01)\end{array}$} & \multicolumn{2}{|c|}{$\begin{array}{l}\text { National } 84 \\
(02-07-01)\end{array}$} & \multicolumn{2}{|c|}{$\begin{array}{l}\text { National } 84 \\
(02-07-01)\end{array}$} \\
\hline \multicolumn{2}{|c|}{ Grid Spacing } & & \multicolumn{2}{|c|}{$\begin{array}{l}3^{\prime} \text { (plus sub-grids } \\
\left.\text { of } 75^{\prime \prime}\right) * *\end{array}$} & \multicolumn{2}{|c|}{$3 \prime$} & \multicolumn{2}{|c|}{$3^{\prime}$} & & \\
\hline \multicolumn{2}{|c|}{ N Pts } & & \multicolumn{2}{|c|}{46} & \multicolumn{2}{|l|}{107} & \multicolumn{2}{|l|}{39} & \multicolumn{2}{|l|}{192} \\
\hline \multicolumn{2}{|c|}{ Areas to watch } & & \multicolumn{2}{|c|}{$\begin{array}{l}\text { (Exmouth, } \\
\text { WA/SA-Border) }\end{array}$} & \multicolumn{2}{|c|}{$\begin{array}{l}\text { (Gt Aust Bight, } \\
\text { Yorke Peninsula, } \\
\text { Vic-Border) }\end{array}$} & \multicolumn{2}{|c|}{$\begin{array}{l}\text { (Longreach, } \\
\text { Charters Towers, } \\
\text { SA/Nsw-NT- } \\
\text { Borders) }\end{array}$} & & \\
\hline \multicolumn{2}{|c|}{ Worst Pt * } & & \multicolumn{2}{|c|}{$\begin{array}{l}1.863 \\
\text { (Exmouth) }\end{array}$} & \multicolumn{2}{|c|}{$\begin{array}{l}0.899 \\
\text { (Vic Border) }\end{array}$} & \multicolumn{2}{|c|}{$\begin{array}{l}0.367 \\
\text { (Charters Tow- } \\
\text { ers) }\end{array}$} & \multicolumn{2}{|c|}{$\begin{array}{l}1.863 \\
\text { (Exmouth, WA) }\end{array}$} \\
\hline \multirow{4}{*}{\multicolumn{2}{|c|}{ GDAit 2.0}} & Min & \multicolumn{2}{|c|}{0.0} & \multicolumn{2}{|c|}{0.002} & \multicolumn{2}{|c|}{0.006} & & \\
\hline & & Max & & 63 & & & & & & \\
\hline & & Std & & 83 & & & & & & \\
\hline & & Mean & & 65 & & 30 & & & & \\
\hline GD & & $\operatorname{Min}$ & & 0 & & & & & & \\
\hline & & Max & & 363 & & & & & & \\
\hline & & Std & & 83 & & 20 & & & & \\
\hline & & Mean & & 65 & & 30 & & & & \\
\hline Geo & & Min & & 0 & & & & & & \\
\hline & & Max & & 60 & & & & & & \\
\hline & & Std & & 82 & & 20 & & & & \\
\hline & & Mean & & 65 & & 30 & & & & \\
\hline
\end{tabular}

** Regions of Broome, Port Hedland, Geraldton, and southwest (3) (Collier, 2002).

When using the Geod 3.30 software, caution must be exercised when converting data from DDD MM SS.sssss to DDD.ddd to be used with the DDD.ddd coordinate transformation input option, to avoid large rounding errors. Data should be converted to a minimum of eight decimal places (DDD.dddddddd) for the input coordinates in order to produce acceptable DDD MM SS.sssss output values (Tables $14 \& 15$ ). 
Table 14. Comparison of transformed GDA94 (from AGD84) and observed GDA94 positional differences of the same station, using nominal DDD.ddd coordinate input with the Geod 3.30 coordinate transformation program.

\begin{tabular}{|c|c|c|c|c|c|c|c|c|}
\hline \multirow[t]{2}{*}{ Stn } & \multicolumn{3}{|c|}{ Lat (Transformed) } & \multicolumn{3}{|c|}{ Long (Transformed) } & \multirow{2}{*}{$\begin{array}{c}\text { Positional } \\
\text { Difference } \\
\text { (m) }\end{array}$} & \multirow{2}{*}{$\begin{array}{c}\text { DDD.ddd } \\
\text { Input }\end{array}$} \\
\hline & Deg & Min & $\mathrm{Sec}$ & Deg & Min & $\mathrm{Sec}$ & & \\
\hline 3814 & 23 & 8 & 57.53334 & 114 & 30 & 23.56741 & 1.777 & 4 \\
\hline 3814 & 23 & 8 & 57.49734 & 114 & 30 & 23.53141 & 0.331 & 5 \\
\hline 3814 & 23 & 8 & 57.50094 & 114 & 30 & 23.52061 & 0.040 & 6 \\
\hline 3814 & 23 & 8 & 57.49914 & 114 & 30 & 23.52097 & 0.017 & 7 \\
\hline 3814 & 23 & 8 & 57.49925 & 114 & 30 & 23.52111 & 0.014 & 8 \\
\hline 3814 & 23 & 8 & 57.49924 & 114 & 30 & 23.52111 & 0.015 & 9 \\
\hline 3814 & 23 & 8 & 57.49924 & 114 & 30 & 23.52111 & 0.015 & 10 \\
\hline
\end{tabular}

Table 15 shows how important it is for users to be aware of rounding errors and their effects on transformed data sets. Stored digital data are especially susceptible to rounding, such as in spreadsheets, and users can easily forget this when transferring the data to the software program.

Table 15. Statistics of 192 transformed GDA94 (AGD84) and observed GDA94 datum differences using nominal DDD.ddd input with the Geod 3.30 coordinate transformation program (units in metres).

\begin{tabular}{|c|c|c|c|c|}
\hline Dec Places & Mean & Std & Max & Min \\
\hline 4 & 4.365 & 1.647 & 7.467 & 1.047 \\
\hline 5 & 0.457 & 0.238 & 1.607 & 0.031 \\
\hline 6 & 0.125 & 0.214 & 1.848 & 0.002 \\
\hline 7 & 0.107 & 0.224 & 1.856 & 0.000 \\
\hline 8 & 0.106 & 0.224 & 1.863 & 0.000 \\
\hline 9 & 0.106 & 0.224 & 1.863 & 0.000 \\
\hline 10 & 0.106 & 0.224 & 1.863 & 0.000 \\
\hline
\end{tabular}




\section{CONCLUDING REMARKS}

For horizontal coordinate transformations from the AGD66 and AGD84 to the GDA94, the so-called Grid Transformation method is the best, due to its ability to model network distortions, as well as its use of significantly more data points than the Molodensky and similarity methods in its estimation. A geoid model is still needed for the vertical datum transformation. The three-dimensional similarity method using ICSM parameters is the best conformal, medium-accuracy transformation for Australia, although the ICSM block shift method compares very well for the AGD66. The abridged Molodensky (ICSM parameters) is the next-best transformation method for Australia. The DMA-estimated transformation parameters, while serving a purpose at the time (1987), are of little use now that the ICSM parameters have been created. Naturally, it is pleasing to see that the new parameters that officially supersede the old parameters are indeed largely superior.

\section{ACKNOWLEDGEMENTS}

The authors extend their appreciation to the following people for their kind assistance with information and donation of data. Jim Steed, Director of Geodetic Information Centre, National Mapping Division, Geoscience Australia (formerly AUSLIG); Dr Phil Collier, Department of Geomatics, University of Melbourne, Victoria; Jim Skates, retired Assistant Manager Geodetic Data Services, Department of Land Information (DLI), Western Australia; Nick Bowden, Office of the Surveyor General, Tasmania; Roger Fraser (GDAy Program Coordinator); Geoff Sandford (South Australian Grid-file Coordinator); Graham Samuel (Geod Program Coordinator). We would like to thank the two anonymous reviewers and Editor for the constructive comments that helped us improve the clarity of presentation.

\section{References}

Allman, J.S. and Veenstra, J.B., (1984) Geodetic Model of Australia 1982, Technical Report 33, Division of National Mapping, Canberra.

Applebaum, L.T. (1982) Geodetic datum transformation by multiple regression equations. Proceedings of the Third International Geodetic Symposium on Satellite Doppler Positioning, Las Cruces, New Mexico, pp. 207-223.

Burford, B.J. (1985) A further examination of datum transformation parameters in Australia, The Australian Surveyor, vol. 32, no. 7, pp. 536-558. 
Collier P.A., Argeseanu V., Leahy F. (1997) Distortion modelling and the transition to GDA94, The Australian Surveyor, vol. 43, no. 1, pp. 29-40.

Collier, P. (2002) Development of Australia's national GDA94 transformation grids, Consultant's Report to the Intergovernmental Committee on Surveying and Mapping, Department of Geomatics, Melbourne, Victoria, Australia.

Featherstone, W.E. (1997) An evaluation of existing coordinate transformation models and parameters in Australia, Cartography, 26(1): 13-26.

Featherstone, W.E. and P. Vaníček (1999) The role of coordinate systems, coordinates and heights in horizontal datum transformations, The Australian Surveyor, vol. 44, no. 2, pp. 143-150.

Featherstone, W.E. and J.M. Rüeger (2000) The importance of using deviations of the vertical in the reduction of terrestrial survey data to a geocentric datum, The TransTasman Surveyor, vol. 1, no. 3, pp. 46-61 [erratum in The Australian Surveyor, vol. 47, no. 1, pp. 7].

Featherstone, W.E. and R Kinneen (2001) Transformation models and parameters in Western Australia - how good are they?, Timepiece (Newsletter of the Western Australian Institute of Surveyors), vol. 2, no. 1, pp. 7-8.

Featherstone, W.E., J.F. Kirby, A.H.W. Kearsley, J.R. Gilliland, G.M. Johnston, J. Steed, R. Forsberg, M.G. Sideris (2001) The AUSGeoid98 geoid model of Australia: data treatment, computations and comparisons with GPS-levelling data, Journal of Geodesy, vol. 75, nos. 5/6, pp. 313-330.

Harvey, B.R. (1986) Transformation of 3D coordinates. The Australian Surveyor, vol. 33, no. 2, pp. 105-125.

Higgins, M.B. (1987) Transformation from WGS84 to AGD84, an interim solution, Internal Report, Department of Geographic Information, The University of Queensland.

ICSM (2002a) Geocentric Datum of Australia Technical Manual, Version 2.2, Intergovernmental Committee on Surveying \& Mapping, Canberra, http://www.icsm.gov.au/icsm/gda/gdatm/index.html 
ICSM (2002b) Standards and Practices for Control Surveys (version 1.5), Intergovernmental Committee on Surveying and Mapping, Canberra, http://www.icsm.gov.au/icsm/publications/sp1/SP1v1-5.pdf

Malays, S. and Slater, J. (1994) Maintenance and enhancement of the World Geodetic System 1984, Proceedings of ION GPS-94, Salt lake City, Utah.

Moritz, H. (1980a) Geodetic Reference System 1980. Bulletin Géodésique, vol. 54, no. 4, pp. 395-405.

Moritz, H. (1980b) Advanced Physical Geodesy, Wichman, Karlsruhe.

NIMA (1997) National Imagery and Mapping Agency, Department of Defense World Geodetic System 1984: its definition and relationships with local geodetic systems (third edition). Technical Report no. 8350.2, National Imagery and Mapping Agency, Washington.

NMC (1986) The Australian Geodetic Datum Technical Manual. Special Publication no. 10, National Mapping Council of Australia, Canberra, 65pp.

Seppelin, T.O. (1974) The Department of Defense World Geodetic System 1972, The Canadian Surveyor, vol. 28, no. 5, pp. 496-506

Steed, J. (1995) The geocentric datum of Australia. Surveying World, vol. 4, no. 1, pp. 14-17.

Soler, T. (1998) A compendium of transformation formulas useful in GPS work, Journal of Geodesy, vol. 72, nos. 7/8, pp. 482-490.

Vincenty, T. (1975) Direct and inverse solutions of geodesics on the ellipsoid with application of nested equations, Survey Review, vol. 22, no. 176, pp. 88-93. 